\title{
The Discovery of Fungal Polyene Macrolides via Postgenomic Approach Reveals a Polyketide Macrocyclization by trans-Acting Thioesterase in Fungi
}

Yohei Morishita, ${ }^{\dagger}$ Huiping Zhang, ${ }^{\ddagger}$ Tohru Taniguchi, ${ }^{,}$Kenji Mori ${ }^{*}$ and Teigo Asai ${ }^{* \dagger}$

${ }^{\dagger}$ Department of Life Sciences, Graduate School of Arts and Sciences, The University of Tokyo

${ }^{\ddagger}$ NMR Science and Development Division, RIKEN Spring-8 Center

${ }^{\S}$ Faculty of Advanced Life Science, Frontier Research Center for Post-Genome Science and Technology, Hokkaido University

"Department of Applied Chemistry, Graduate School of Engineering Tokyo University of Agriculture and Technology

Table of contents

SI-2: General Experimental Procedure, Figure S1, Biosynthetic gene donating fungal material.

SI-3: Experimental Section.

SI-4: Figure S2. 2D NMR correlation of compound 1.

SI-5: $\quad$ Table S1. ${ }^{13} \mathrm{C}(226 \mathrm{MHz})$ and ${ }^{1} \mathrm{H}(900 \mathrm{MHz})$ NMR data for $\mathbf{1}$.

SI-6: Figure S3. 2D NMR correlation of compound 3.

SI-7: $\quad$ Table S2. ${ }^{13} \mathrm{C}(200 \mathrm{MHz})$ and ${ }^{1} \mathrm{H}(800 \mathrm{MHz}) \mathrm{NMR}$ data for 3.

SI-8: $\quad$ Figure S4. 2D NMR correlation of compound 4.

SI-9: $\quad$ Table S3. ${ }^{13} \mathrm{C}(226 \mathrm{MHz})$ and ${ }^{1} \mathrm{H}(900 \mathrm{MHz})$ NMR data for 4.

SI-10: Fragmentation and chemical derivatization of $\mathbf{3}$.

SI-12: Preparation and NMR data of $\mathbf{8 , 9 .}$

SI-13: Preparation and NMR data of 10, 11.

SI-14: Advanced Mosher's analyses and NMR data of $\mathbf{8 a}, \mathbf{8 b}, \mathbf{1 0 a}$ and $\mathbf{1 0 b}$.

SI-15: Figure S5. Comparison of HPLC profiles of AO-apmlA+apmlB and A. phaeospermum.

SI-16: Figure S6. Phylogenetic analysis of DH domains of HR-PKSs.

SI-17: Figure S7. Phylogenetic analysis of ApmlB and selected fungal TEs and TE domains.

SI-18: Figure S8. Phylogenetic analysis of HR-PKSs.

SI-19: Table S4 and nucleotide/amid acid sequence of apmlA and apmlB.

SI-21: Table S5-S7.

SI-22: NMR spectra of compound $\mathbf{1}$.

SI-30: NMR spectra of compound 3.

SI-37: NMR spectra of compound 4. 


\section{General experimental procedure}

Analytical TLC were performed on silica gel 60 F254 (Merck) and RP-18 F254 (Merck). Column chromatography was carried out on silica gel 60 (70-230 and 40-50 mesh), Cosmosil 140 C18-OPN (nacalai tesque). The $500 \mathrm{MHz}$ NMR spectra were recorded on a Bruker AVANCE III 500 spectrometer $\left({ }^{1} \mathrm{H}\right.$ NMR, $500 \mathrm{MHz} ;{ }^{13} \mathrm{C}$ NMR, $\left.126 \mathrm{MHz}\right)$. The $800 \mathrm{MHz}$ NMR spectra were recorded on a Bruker AVANCE III HD 900 spectrometer $\left({ }^{1} \mathrm{H}\right.$ NMR, $800 \mathrm{MHz} ;{ }^{13} \mathrm{C}$ NMR, $\left.201 \mathrm{MHz}\right)$. The $900 \mathrm{MHz}$ NMR spectra were recorded on a Bruker AVANCE III HD 900 spectrometer $\left({ }^{1} \mathrm{H}\right.$ NMR, $900 \mathrm{MHz} ;{ }^{13} \mathrm{C}$ NMR, $\left.226 \mathrm{MHz}\right)$. Chemical shifts for $1 \mathrm{H}$ and ${ }^{13} \mathrm{C}$ NMR are given in parts per million $(\delta)$ relative to tetramethylsilane $\left(\delta_{\mathrm{H}} 0.00\right)$ and residual solvent signals $\left(\delta_{\mathrm{C}} 77.0\right)$ for $\mathrm{CDCl}_{3},\left(\delta_{\mathrm{H}} 2.49, \delta_{\mathrm{C}} 39.7\right)$ for DMSO- $d_{6}$ as internal standards. Mass spectra were measured on Exactive Orbitrap Mass Spectrometer (Thermo Fischer Scientific). IR and VCD spectra were measured on a JASCO FVS-6000 spectrometer. UV spectra were recorded on a JASCO-V-730 spectrophotometer. HPLC analysis was performed on a JASCO AS-1555-10 Intelligent Sampler, JASCO PU-4180 RHPLC Pump and JASCO MD-4017 Photo Diode Array Detector (JASCO), which equipped with COSMOSIL Packed Column 5C18-MS-II $(\phi 4.6 \mathrm{~mm} \times 150 \mathrm{~mm}$ ) (nacalai tesque). LC-MS analysis was performed on a Chrommaster 5610 MS Detector (HITACHI, Ltd), a Chromaster 5110 Pump (HITACHI, Ltd) and Chromaster 5430 Diode Array Detector (HITACHI, Ltd), which equipped with COSMOSIL Packed Column 5C18-MS-II ( $\phi 4.6 \mathrm{~mm} \times 150 \mathrm{~mm}$ ) (nacalai tesque).

Figure S1. Examples of fungal aliphatic macrolides<smiles>C[C@H]1CCC(=O)/C=C\[C@H](O)CC(=O)O1</smiles>

Cephalosporolide B<smiles>CC1CCC/C=C/[C@@H]2C[C@H](O)C[C@H]2C/C=C/C(=O)O1</smiles>

Brefeldin A<smiles>CC1CCCCCCCCC[C@@H](O)C(=O)[C@H](CC(=O)OC[C@H](O)C(=O)O)SC1</smiles>

Berkeleylactone A

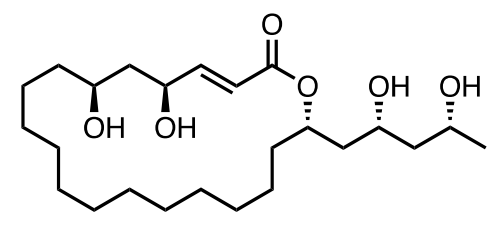

Rickiol A

\section{Biosynthetic gene donating fungal material}

Arthrinium phaeospermum Kemushi-1 was isolated from the surface-sterilized a hairy caterpillar collected in 2013 in the Campus of Tohoku University. The fungus (Strain Kemushi-1) was identified by 28S rDNA gene D1/D2 region sequencing and species identification. The fungus was cultured in potato dextrose agar and the mycelium was ground to a fine powder in liquid $\mathrm{N}_{2}$. Genomic DNA was extracted using the Wizard Genomic DNA Purification Kit (Promega), and 28S rDNA gene D1/D2 region was amplified by PCR using primers (5'-GCATATCAATAAGCGGAGGAAAAG-3') and NL4 (5'-GGTCCGTGTTTCAAGACGG-3'). PCR products were sequenced (ABI PRISMTM 310 Genetic Analyzer). The following consensus sequence was used in a BLAST search against deposited sequences.

5'-GCATATCAATAAGCGGAGGAAAAGAAACCAACAGGGATTCCCCTAGTAACGGCGAGTGAA GCGGGAACAGCTCAAATTTGAAATCTGGCCCTTGGGTCCGAGTTGTAATTTGCAGAGGATGC TTTTGGTGCGGTGCCTTCCGAGTTCCCTGGAACGGGACGCCTTAGAGGGTGAGAGCCCCGT ACGGTTGGACACCAAGCCTATGTAAAGCTCCTTCGACGAGTCGAGTAGTTTGGGAATGCTGC TCAAAATGGGAGGTATATTTCTTCTAAAGCTAAATATTGGCCAGAGACCGATAGCGCACAAGT AGAGTGATCGAAAGATGAAAAGCACTTTGAAAAGAGGGTTAAATAGCACGTGAAATTGTTGAA AGGGAAGGATTTATGACCAGACTTTTTCTAGGGGGATCATCCGGTGTTCTCACTGGTGCACTT CCCCTAGTTGAGGCCAGCATCGGTTTCTGTCGAGGGATAAAAGCTTTAGGAATGTGGCACCC 

AGGATGCTGGCGTAATGGTTATTAATCACCCGTCTTGAAACACGGACC-3'

\section{Heterologous host strain}

Asperillus oryzae NSAR1 (niaD ${ }^{-}, s C^{-}, \Delta \arg B, a d e A^{-}$) was used as the host for fungal expression.

\section{Construction of the apmlA, apmlB coexpression system}

The genes were amplified by PrimeSTAR ${ }^{\circledR}$ MAX DNA Polymerase (TAKARA) with primers in Table S5. Escherichia coli DH5 $\alpha$ were used for cloning, following standard recombinant DNA techniques. Fungal expression plasmid pUARA2 or pUAdeA2 possessing the $\alpha$-amylase promoter (amyB) of $A$. oryzae and auxotrophic marker $\arg B$ or adeA of $A$. nidulans respectively was used. The apmlA was divided into two equal-sized flagments; each flagment was amplified with the primers apmlA_IFpUKpnI-FW and apmlA_R1, or apmlA_F1 and apmlA_IFpUKpnI-RV. The apmlB gene was amplified with the primers $a p m l B \_I F p U N o t I-F W$ and $a p m l B \_I F p U N o t I-R V$. The PCR products were purified. The resultant fragment apmlA was subcloned into pUARA2 which had been digested with KpnI to yield pUARA2-apmlA. The apmlB was subcloned into pUAdeA2 which had been digested with NotI to yield pUAdeA2-apmlB. The apmlA and $a p m l B$ were subcloned into pUARA2 which had been digested with KpnI and NotI to yield pUARA2-apmlAB. A. oryzae NSAR1 was transformed with pUARA2-apmlAB or pUARA2-apmlA to construct $\mathrm{AO}-a p m l A B$ or $\mathrm{AO}-a p m l A$ respectively. The transformant $\mathrm{AO}-$ apmlA was transformed with pUAdeA2-apmlB to construct AO-apmlA+apmlB.

\section{Culture medium for AO-apmlAB, AO-apmlA, AO-apmlA+apmlB or control}

CPS medium (+ adenine): $1.75 \%$ Czapek-Dox Broth, $0.17 \%$ Meat peptone, $0.17 \%$ Soy peptone, $0.17 \%$

Casein peptone, $1.0 \%$ Soluble Starch, $0.5 \%$ Maltose H, $1.5 \%$ Adenine sulfate dihydrate in $60 / 150 \mathrm{~mL}$

Distilled water.

\section{Cultivation of the transformants in CPS medium and HPLC analysis}

The transformants were cultivated on a selection agar plant at $30^{\circ} \mathrm{C}$ and its mycelia were inoculated in CPS medium and incubated at $30^{\circ} \mathrm{C}$ for 5 days. The cultured mycelia were harvested and freeze-dried. The $40 \mathrm{mg}$ of the crushed mycelia was extracted with $1 \mathrm{~mL} \mathrm{MeOH}$ for $30 \mathrm{~min}$. After centrifuged at 13,500 rpm for $15 \mathrm{~min}, 500 \mu \mathrm{L}$ was transferred to a new tube and concentrated under reduced pressure to obtain $\mathrm{MeOH}$ extract. The extract was resuspended with $100 \mu \mathrm{L} \mathrm{MeOH}$, centrifuged again, and $10 \mu \mathrm{L}$ was injected into HPLC. Flow rate; $1 \mathrm{~mL} / \mathrm{min}$, Solvent gradient system: acetonitrile and water with $0.01 \%$ TFA (0-2 min: 20:80, 2-12 min: 20:80 to 100: 0, 12-24 min: 100:0). Absorbance was monitored at $380 \mathrm{~nm}$.

\section{Isolation of compound 1 and mixture of 2}

AO- $a p m l A B$ was cultivated in CPS medium $\left(3.6 \mathrm{~L} ; 150 \mathrm{~mL}\right.$ x 24) at $30^{\circ} \mathrm{C}$ for 5 days. The cultured mycelia were harvested, freeze-dried, crushed to powder and extracted with $\mathrm{MeOH}$ twice, and the extracts $(3.2 \mathrm{~g})$ were obtained. The pyridine soluble fraction was subjected to flash silica gel (c.a. $3 \mathrm{cc}$ ) and the solvent was evaporated for 1 hour under vacuum. The silica gel was loaded onto silica gel column chromatography 
eluted with $\mathrm{CHCl}_{3}-\mathrm{MeOH}(19 / 1-9 / 1)$ to give $\mathbf{1}(4.1 \mathrm{mg})$ and clude 2 (2.3 mg). The clude 2 was analyzed by ESIMS and determined its molecular formula as $\mathrm{C}_{32} \mathrm{H}_{46} \mathrm{O}_{7}\left(\mathrm{~m} / z 565.3124[\mathrm{M}+\mathrm{Na}]^{+}\right.$, calcd 565.3136). 


\section{Compound 1}

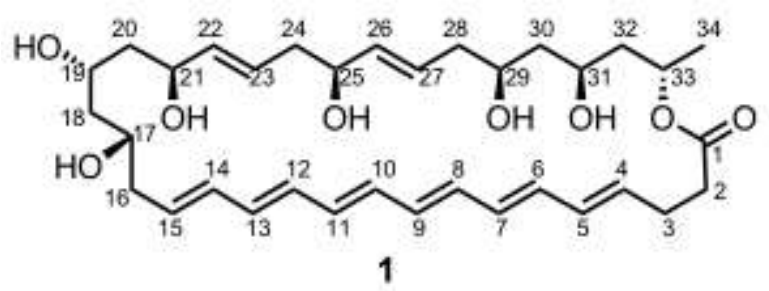

The molecular formula of $\mathbf{1}$, pale yellow powder, was determined as $\mathrm{C}_{34} \mathrm{H}_{50} \mathrm{O}_{8}$ from the 1D NMR spectra and the ion peaks at $\mathrm{m} / \mathrm{z} 609.3366\left([\mathrm{M}+\mathrm{Na}]^{+}\right.$, calcd 609.3398) in the HRESIMS spectrum, implying nine degrees of unsaturation. NMR spectra of $\mathbf{1}$ were obtained in DMSO- $d_{6}$. The assignments of all proton and carbon resonances, listed in Table S1, were achieved by various 2D NMR experiments measured at 900 MHz. The UV spectrum (log $\varepsilon$ ) showing 4 bands at 325 (4.77), 339 (4.75), 357 (4.53), and 377 (4.23) nm and the yellow color suggested a conjugated hexaene moiety of $\mathbf{1}$. The connection of C-2 to C-6 and C-13 to $\mathrm{C}-34$ were characterized by ${ }^{1} \mathrm{H}-{ }^{1} \mathrm{H}$ COSY, HMBC, ${ }^{1} \mathrm{H}-{ }^{1} \mathrm{H}$ TOCSY and HSQC-TOCSY experiment (Figure S1). Considering with the presence of a conjugated hexaene and the chemical shift value of the remained olefin carbons, C-4 to C-14 ( $\delta_{\mathrm{C}} 131.6$ to $\left.\delta_{\mathrm{C}} 133.5\right)$ were suggested to connect with the conjugated hexaene moiety. Characteristic ester carbonyl carbon signal at C-1 $\left(\delta_{\mathrm{C}} 172.4\right)$ and HMBC correlation of the carbonyl signal with the downfield side oxymethine $\mathrm{H}-33\left(\delta_{\mathrm{H}} 5.05\right)$ indicated the formation of 34-membered lactone ring. 16 olefin carbons, 12 of them in conjugated hexaene, and the double bond equivalent indicated the presence of additional two olefins. The $J$ values of the olefin protons between $\mathrm{H}-22 / \mathrm{H}-23\left(\delta_{\mathrm{H}} 5.34\right.$ and $\delta_{\mathrm{H}}$ 5.41), and H-26/H-27 ( $\delta_{\mathrm{H}} 5.36$ and $\left.\delta_{\mathrm{H}} 5.50\right)$ were 15.3, and the NOESY correlation between H-21/H-23, $\mathrm{H}-22 / \mathrm{H}-24, \mathrm{H}-25 / \mathrm{H}-27$ and $\mathrm{H}-26 / \mathrm{H}-28$ were observed, suggesting the $E$-conformation of the two distinct olefins. The six oxymethine proton $\left(\delta_{\mathrm{H}} 3.6-3.9\right)$ and the six broad doublet signals $\left(\delta_{\mathrm{H}} 4.4-4.7\right)$, in which ${ }^{1} \mathrm{H}-{ }^{1} \mathrm{H}$ COSY correlation were observed respectively, showed six hydroxy group. From the data above, we decided the overall 2D structure of $\mathbf{1}$ as shown. The locations of all olefins and hydroxy groups were not inconsistent with the biosynthetic mechanism of a common fungal HR-PKS.

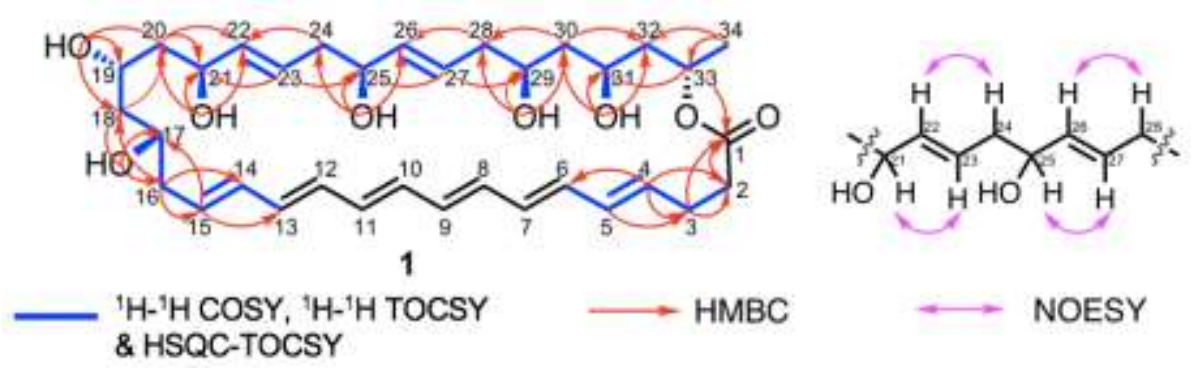

Figure S2. 2D NMR correlation of compound 1.

${ }^{1} \mathrm{H}-{ }^{1} \mathrm{H}$ COSY, ${ }^{1} \mathrm{H}-{ }^{1} \mathrm{H}$ TOCSY and HSQC-TOCSY (bold blue line), key HMBC (red arrow) and NOESY (purple arrow) correlations. The assignments of all proton and carbon resonances were listed in Table S1. 
Table S1. ${ }^{13} \mathrm{C}(226 \mathrm{MHz})$ and ${ }^{1} \mathrm{H}(900 \mathrm{MHz})$ NMR data for $\mathbf{1}^{\mathrm{a}, \mathrm{b}}$.

\begin{tabular}{|c|c|c|c|c|c|}
\hline Position & ${ }^{13} \mathrm{C}$ & ${ }^{1} \mathrm{H}$ & Position & ${ }^{13} \mathrm{C}$ & ${ }^{1} \mathrm{H}$ \\
\hline 1 & 172.2 & & 21 & 69.5 & $3.89(1 \mathrm{H}, \mathrm{m})$ \\
\hline \multirow[t]{2}{*}{2} & \multirow[t]{2}{*}{34.0} & $2.36(1 \mathrm{H}, \mathrm{m})$ & 22 & 135.9 & $5.34(1 \mathrm{H}, \mathrm{dd}, 15.3,6.6)$ \\
\hline & & $2.39(1 \mathrm{H}, \mathrm{m})$ & 23 & 127.1 & $5.41(1 \mathrm{H}, \mathrm{dt}, 15.3,6.8)$ \\
\hline 3 & 28.1 & $2.35(2 \mathrm{H}, \mathrm{m})$ & \multirow[t]{2}{*}{24} & \multirow[t]{2}{*}{41.0} & $1.96(1 \mathrm{H}, \mathrm{m})$ \\
\hline 4 & 133.1 & $5.71(1 \mathrm{H}, \mathrm{m})$ & & & $2.03(1 \mathrm{H}, \mathrm{m})$ \\
\hline 5 & 131.7 & $6.11(1 \mathrm{H}, \mathrm{m})$ & 25 & 71.0 & $3.83(1 \mathrm{H}, \mathrm{m})$ \\
\hline \multirow[t]{3}{*}{6} & 131.9 & \multirow[t]{3}{*}{$6.22(1 \mathrm{H}, \mathrm{m})$} & 26 & 135.8 & $5.36(1 \mathrm{H}, \mathrm{dd}, 15.3,6.0)$ \\
\hline & 132.8 & & 27 & 126.6 & $5.50(1 \mathrm{H}, \mathrm{dd}, 15.3,7.6)$ \\
\hline & 132.9 & & 28 & 40.9 & $1.89(1 \mathrm{H}, \mathrm{m})$ \\
\hline \multirow{4}{*}{$7-12^{\mathrm{c}}$} & 133.0 & \multirow{4}{*}{$6.28-6.31(6 \mathrm{H})$} & & & $2.03(1 \mathrm{H}, \mathrm{m})$ \\
\hline & 133.1 & & 29 & 69.7 & $3.61(1 \mathrm{H}, \mathrm{m})$ \\
\hline & 133.2 & & 30 & 44.2 & $1.32(2 \mathrm{H}, \mathrm{m})$ \\
\hline & 133.2 & & 31 & 66.9 & $3.60(1 \mathrm{H}, \mathrm{m})$ \\
\hline 13 & 131.4 & $6.24(1 \mathrm{H}, \mathrm{m})$ & 32 & 44.4 & $1.42(1 \mathrm{H}, \mathrm{m})$ \\
\hline 14 & 133.2 & $6.11(1 \mathrm{H}, \mathrm{m})$ & & & $1.57(1 \mathrm{H}, \mathrm{m})$ \\
\hline 15 & 131.3 & $5.73(1 \mathrm{H}, \mathrm{m})$ & 33 & 68.0 & $5.03(1 \mathrm{H}, \mathrm{m})$ \\
\hline \multirow[t]{2}{*}{16} & \multirow[t]{2}{*}{40.0} & $2.20(1 \mathrm{H}, \mathrm{m})$ & 34 & 21.1 & $1.16(3 \mathrm{H}, \mathrm{d}, 6.2)$ \\
\hline & & $2.34(1 \mathrm{H}, \mathrm{m})$ & $17-\mathrm{OH}$ & & $4.53(1 \mathrm{H}, \mathrm{brd}, 3.6)$ \\
\hline 17 & 67.5 & $5.73(1 \mathrm{H}, \mathrm{m})$ & $19-\mathrm{OH}$ & & $4.40(1 \mathrm{H}, \mathrm{brd}, 4.1)$ \\
\hline \multirow[t]{2}{*}{18} & \multirow[t]{2}{*}{44.2} & $1.32(1 \mathrm{H}, \mathrm{m})$ & $21-\mathrm{OH}$ & & $4.50(1 \mathrm{H}$, brd, 3.9) \\
\hline & & $1.50(1 \mathrm{H}, \mathrm{m})$ & $25-\mathrm{OH}$ & & $4.38(1 \mathrm{H}, \mathrm{brd}, 4.0)$ \\
\hline 19 & 66.0 & $3.51(1 \mathrm{H}, \mathrm{m})$ & $29-\mathrm{OH}$ & & $4.60(1 \mathrm{H}, \mathrm{brd}, 3.9)$ \\
\hline \multirow[t]{2}{*}{20} & \multirow[t]{2}{*}{47.1} & $1.26(1 \mathrm{H}, \mathrm{m})$ & $31-\mathrm{OH}$ & & $4.60(1 \mathrm{H}, \mathrm{brd}, 4.3)$ \\
\hline & & $1.56(1 \mathrm{H}, \mathrm{m})$ & & & \\
\hline
\end{tabular}

[a] Assignments were based on ${ }^{1} \mathrm{H}-{ }^{1} \mathrm{H}$ COSY, HSQC, HMBC, ${ }^{1} \mathrm{H}-{ }^{1} \mathrm{H}$ TOCSY, HSQC-TOCSY experiments.

[b] Recorded in DMSO-d6.

[c] The assignments of ${ }^{1} \mathrm{H}$ and ${ }^{13} \mathrm{C}$ signals for $\mathrm{C}-7$ to $\mathrm{C}-12$ were exchangeable each other. 


\section{Synthesis and isolation of 3}

In order to obtain acetylated derivative 3, we carried re-cultivation of AO-apmlAB in CPS medium (9.8 L; $150 \mathrm{~mL} \times 65)$ at $30^{\circ} \mathrm{C}$ for 5 days. The $\mathrm{MeOH}$ extract was roughly separated by silica gel $\left(\mathrm{CHCl}_{3}-\mathrm{MeOH}=\right.$ 9/1) to give the mixture contained $1(87.2 \mathrm{mg})$. The mixture was reacted with acetic anhydride $(500 \mu \mathrm{L}, 5.3$ $\mathrm{mmol}$ ) in $1 \mathrm{~mL}$ pyridine at room temperature for 12 hours. The reaction mixture was evaporated and dried under vacuum. The reaction mixture was subjected to flash silica gel column chromatography eluted with $\mathrm{CHCl}_{3}$-EtOAc (4/1) to give clude $\mathbf{3}(44.0 \mathrm{mg})$. The $1.0 \mathrm{mg}$ of the clude $\mathbf{3}$ was further purified by preparative TLC $(n$-hexane-EtOAc $=3 / 1)$ to give pure $3(0.6 \mathrm{mg})$.

\section{Compound 3}

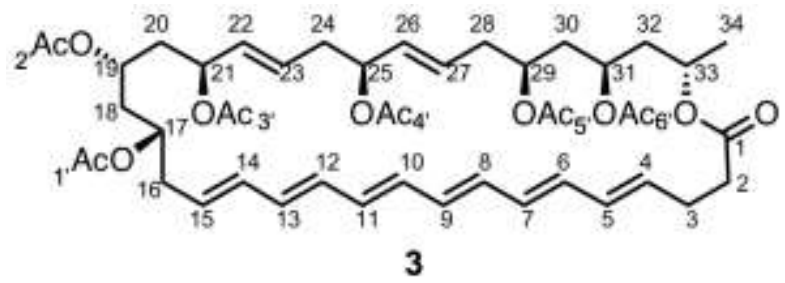

3: Pale yellow powder; HRESIMS: $m / z 861.3990[\mathrm{M}+\mathrm{Na}]^{+}\left(861.4032\right.$ calcd. for $\mathrm{C}_{46} \mathrm{H}_{62} \mathrm{O}_{14} \mathrm{Na}$ ), The assignments of all proton and carbon resonances, achieved by various 2D NMR experiments measured at $800 \mathrm{MHz}$, were listed in Table S2.

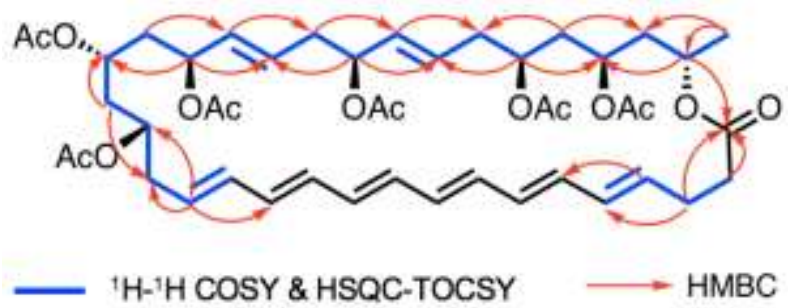

Figure S3. 2D NMR correlation of compound 3.

${ }^{1} \mathrm{H}-{ }^{1} \mathrm{H}$ COSY, HSQC-TOCSY (bold blue line), and key HMBC (red arrow) correlations. 
Table S2. ${ }^{13} \mathrm{C}(200 \mathrm{MHz})$ and ${ }^{1} \mathrm{H}(800 \mathrm{MHz})$ NMR data for $\mathbf{3}^{\mathrm{a}, \mathrm{b}}$.

\begin{tabular}{|c|c|c|c|c|c|}
\hline Position & ${ }^{13} \mathrm{C}$ & ${ }^{1} \mathrm{H}$ & Position & ${ }^{13} \mathrm{C}$ & ${ }^{1} \mathrm{H}$ \\
\hline 1 & 172.3 & & 23 & 130.1 & $5.54(1 \mathrm{H}, \mathrm{m})$ \\
\hline \multirow[t]{2}{*}{2} & 34.5 & $2.35(1 \mathrm{H}, \mathrm{m})$ & 24 & 38.0 & $2.20(2 \mathrm{H}, \mathrm{m})$ \\
\hline & & $2.45(1 \mathrm{H}, \mathrm{m})$ & 25 & 72.9 & $5.15(1 \mathrm{H}, \mathrm{m})$ \\
\hline \multirow[t]{2}{*}{3} & 28.2 & $2.36(1 \mathrm{H}, \mathrm{m})$ & 26 & 131.5 & $5.32(1 \mathrm{H}, \mathrm{dd}, 15.5,7.2)$ \\
\hline & & $2.49(1 \mathrm{H}, \mathrm{m})$ & 27 & 128.7 & $5.51(1 \mathrm{H}, \mathrm{m})$ \\
\hline 4 & 133.4 & $5.79(1 \mathrm{H}, \mathrm{m})$ & 28 & 37.8 & $2.08(1 \mathrm{H}, \mathrm{m})$ \\
\hline 5 & 132.0 & $6.17(1 \mathrm{H}, \mathrm{m})$ & & & $2.27(1 \mathrm{H}, \mathrm{m})$ \\
\hline 6 & 132.2 & $6.25(1 \mathrm{H}, \mathrm{m})$ & 29 & 69.8 & $4.89(1 \mathrm{H}, \mathrm{m})$ \\
\hline \multirow{6}{*}{$7-12^{\mathrm{c}}$} & 131.4 & \multirow{6}{*}{$6.21-6.36(6 \mathrm{H})$} & 30 & 38.7 & $1.61(1 \mathrm{H}, \mathrm{m})$ \\
\hline & 132.5 & & & & $1.78(1 \mathrm{H}, \mathrm{m})$ \\
\hline & 132.6 & & 31 & 68.1 & $4.90(1 \mathrm{H}, \mathrm{m})$ \\
\hline & 133.6 & & 32 & 40.7 & $1.68(2 \mathrm{H}, \mathrm{m})$ \\
\hline & 133.7 & & 33 & 67.1 & $4.95(1 \mathrm{H}, \mathrm{m})$ \\
\hline & 133.8 & & 34 & 20.6 & $1.18(3 \mathrm{H}, \mathrm{d}, 6.2)$ \\
\hline 13 & 132.4 & $6.28(1 \mathrm{H}, \mathrm{m})$ & Ac- $1^{\prime}$ & $170.5^{c}$ & \\
\hline 14 & 134.7 & $6.24(1 \mathrm{H}, \mathrm{m})$ & & $21.3^{d}$ & $2.04^{e}(3 \mathrm{H}, \mathrm{s})$ \\
\hline 15 & 128.1 & $5.68(1 \mathrm{H}, \mathrm{m})$ & Ac- $2^{\prime}$ & $170.3^{c}$ & \\
\hline \multirow[t]{2}{*}{16} & 36.8 & $2.37(1 \mathrm{H}, \mathrm{m})$ & & $21.2^{d}$ & $2.04^{e}(3 \mathrm{H}, \mathrm{s})$ \\
\hline & & $2.47(1 \mathrm{H}, \mathrm{m})$ & Ac- $3^{\prime}$ & 169.7 & \\
\hline 17 & 70.2 & $4.89(1 \mathrm{H}, \mathrm{m})$ & & 21.0 & $2.00(3 \mathrm{H}, \mathrm{s})$ \\
\hline \multirow[t]{2}{*}{18} & 38.2 & $1.78(1 \mathrm{H}, \mathrm{m})$ & Ac- $4^{\prime}$ & $170.1^{c}$ & \\
\hline & & $1.84(1 \mathrm{H}, \mathrm{m})$ & & $21.1^{d}$ & $2.03^{e}(3 \mathrm{H}, \mathrm{s})$ \\
\hline 19 & 68.1 & $4.90(1 \mathrm{H}, \mathrm{m})$ & Ac- $5^{\prime}$ & 169.8 & \\
\hline \multirow[t]{2}{*}{20} & 40.3 & $1.66(1 \mathrm{H}, \mathrm{m})$ & & 21.0 & $1.98(3 \mathrm{H}, \mathrm{s})$ \\
\hline & & $1.93(1 \mathrm{H}, \mathrm{m})$ & Ac- $6^{\prime}$ & $170.1^{c}$ & \\
\hline 21 & 71.7 & $5.10(1 \mathrm{H}, \mathrm{m})$ & & $21.1^{d}$ & $1.97^{e}(3 \mathrm{H}, \mathrm{s})$ \\
\hline 22 & 130.5 & $5.36(1 \mathrm{H}, \mathrm{dd}, 15.4,7.6)$ & & & \\
\hline
\end{tabular}

[a] Assignments were based on ${ }^{1} \mathrm{H}^{-1} \mathrm{H}$ COSY, HSQC, HMBC, HSQC-TOCSY and NOESY experiments.

[b] Recorded in $\mathrm{CDCl}_{3}$. [c] Interchangeable. [d] Interchangeable. [e] Interchangeable.

[c] The assignments of ${ }^{1} \mathrm{H}$ and ${ }^{13} \mathrm{C}$ signals for $\mathrm{C}-7$ to $\mathrm{C}-12$ were exchangeable each other. 


\section{Synthesis and isolation of 4}

The clude 2 was washed by $\mathrm{CHCl}_{3}$ and the insoluble fraction $(0.87 \mathrm{mg})$ was reacted with acetic anhydride $(100 \mu \mathrm{L}, 1.06 \mathrm{mmol})$ in $50 \mu \mathrm{L}$ pyridine for 15 hours. The reaction mixture was evaporated and dried under vacuum. The same reaction $(0.87 \mathrm{mg})$ was conducted again to increase the amount. The reaction mixture $(1.8$ $\mathrm{mg}$ ) was separated by PTLC ( $n$-hexane: EtOAc $=1 / 1)$ to give $4(0.4 \mathrm{mg})$.

\section{Compound 4}

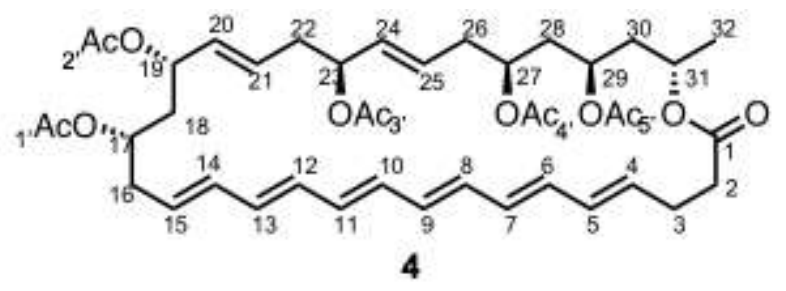

4: Pale yellow powder; HRESIMS: $m / z 775.3639[\mathrm{M}+\mathrm{Na}]^{+}$(775.3664 calcd. for $\mathrm{C}_{42} \mathrm{H}_{56} \mathrm{O}_{12} \mathrm{Na}$ ), NMR spectra of 4 were obtained in $\mathrm{CDCl}_{3}$. The assignments of all proton and carbon resonances, listed in Table S3, were achieved by various 2D NMR experiments measured at $900 \mathrm{MHz}$. The sequential correlations of ${ }^{1} \mathrm{H}-{ }^{1} \mathrm{H}$ COSY and HSQC-TOCSY coupled with the HMBC and HSQC spectral analyses revealed the partial structures of $\mathrm{C}-14$ to $\mathrm{C}-32$ and $\mathrm{C}-2$ to $\mathrm{C}-5$. The HMBC correlations of $\mathrm{H}-31 / \mathrm{C}-1$ revealed connectivity between $\mathrm{C}-1$ and $\mathrm{C}-31$ through ester linkage. The remaining six $\mathrm{sp}_{2}$ carbons were set between $\mathrm{C}-5$ and $\mathrm{C}-14$ to form an all-trans hexaene. The $E$ configuration of the $\Delta^{20,21}$ and $\Delta^{24,25}$ were characterized by vicinal couplings at $J_{20,21}$ of $15.5 \mathrm{~Hz}$ and at $J_{24,25}$ of $15.4 \mathrm{~Hz}$. Thus, the planar structure of 4, with 32-membered macrolactone rings and an all-trans hexaene, was elucidated as depicted.

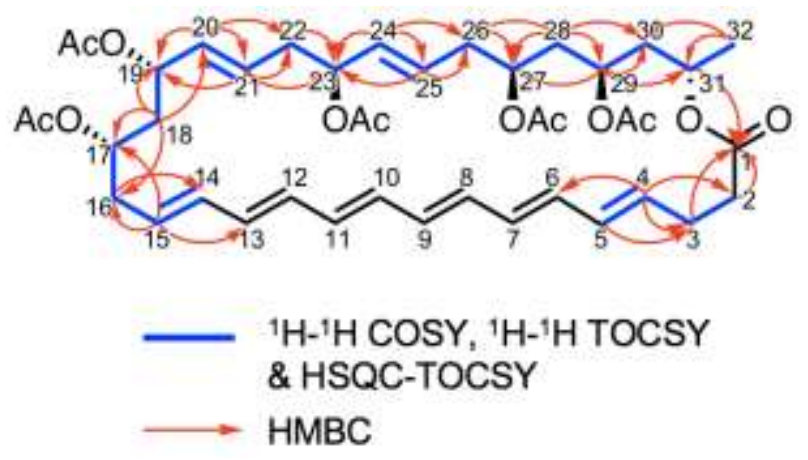

Figure S4. 2D NMR correlation of compound 4.

${ }^{1} \mathrm{H}-{ }^{1} \mathrm{H}$ COSY, ${ }^{1} \mathrm{H}-{ }^{1} \mathrm{H}$ TOCSY and HSQC-TOCSY (bold blue line) and key HMBC correlation (red arrow). The assignments of all proton and carbon resonances were listed in Table S3. 
Table S3. ${ }^{13} \mathrm{C}(226 \mathrm{MHz})$ and ${ }^{1} \mathrm{H}(900 \mathrm{MHz})$ NMR data for $\mathbf{4}^{\mathrm{a}, \mathrm{b}}$.

\begin{tabular}{|c|c|c|c|c|c|}
\hline Position & ${ }^{13} \mathrm{C}$ & ${ }^{1} \mathrm{H}$ & Position & ${ }^{13} \mathrm{C}$ & ${ }^{1} \mathrm{H}$ \\
\hline 1 & 172.4 & & 22 & 37.8 & $2.27(1 \mathrm{H}, \mathrm{m})$ \\
\hline \multirow[t]{2}{*}{2} & 34.3 & $2.36(1 \mathrm{H}, \mathrm{m})$ & & & $2.23(1 \mathrm{H}, \mathrm{m})$ \\
\hline & & $2.46(1 \mathrm{H}, \mathrm{m})$ & 23 & 73.3 & $5.12(1 \mathrm{H}, \mathrm{m})$ \\
\hline \multirow[t]{2}{*}{3} & 28.3 & $2.51(1 \mathrm{H}, \mathrm{m})$ & 24 & 131.1 & $5.34(1 \mathrm{H}, \mathrm{dd}, 15.4,7.4)$ \\
\hline & & $2.36(1 \mathrm{H}, \mathrm{m})$ & 25 & 129.4 & $5.53(1 \mathrm{H}, \mathrm{ddd}, 15.4,8.4,5.7)$ \\
\hline 4 & 133.4 & $5.82(1 \mathrm{H}, \mathrm{m})$ & 26 & 38.3 & $2.20(1 \mathrm{H}, \mathrm{m})$ \\
\hline 5 & 132.2 & $6.18(1 \mathrm{H}, \mathrm{m})$ & & & $2.23(1 \mathrm{H}, \mathrm{m})$ \\
\hline 6 & 133.8 & $6.39(1 \mathrm{H}, \mathrm{m})$ & 27 & 69.7 & $4.94(1 \mathrm{H}, \mathrm{m})$ \\
\hline \multirow{6}{*}{$7-12$} & 131.2 & \multirow{6}{*}{$6.24-6.41(6 \mathrm{H})$} & 28 & 39.0 & $1.61(1 \mathrm{H}, \mathrm{m})$ \\
\hline & 132.1 & & & & $1.78(1 \mathrm{H}, \mathrm{m})$ \\
\hline & 132.1 & & 29 & 68.2 & $4.91(1 \mathrm{H}, \mathrm{m})$ \\
\hline & 132.8 & & 30 & 40.8 & $1.68(2 \mathrm{H}, \mathrm{m})$ \\
\hline & 133.8 & & 31 & 67.2 & $4.94(1 \mathrm{H}, \mathrm{m})$ \\
\hline & 134.0 & & 32 & 20.6 & $1.20(3 \mathrm{H}, \mathrm{d}, 6.3)$ \\
\hline 13 & 131.6 & $6.26(1 \mathrm{H}, \mathrm{m})$ & Ac- $1^{\prime}$ & $170.3^{c}$ & \\
\hline 14 & 135.4 & $6.23(1 \mathrm{H}, \mathrm{m})$ & & $21.2^{d}$ & $2.05^{e}(3 \mathrm{H}, \mathrm{s})$ \\
\hline 15 & 127.5 & $5.66(1 \mathrm{H}, \mathrm{m})$ & Ac- $2^{\prime}$ & $170.2^{c}$ & \\
\hline \multirow[t]{2}{*}{16} & 36.8 & $2.38(1 \mathrm{H}, \mathrm{m})$ & & $21.3^{d}$ & $2.06^{e}(3 \mathrm{H}, \mathrm{s})$ \\
\hline & & $2.52(1 \mathrm{H}, \mathrm{m})$ & Ac- $3^{\prime}$ & 169.9 & \\
\hline 17 & 70.3 & $4.87(1 \mathrm{H}, \mathrm{m})$ & & 21.1 & $2.02(3 \mathrm{H}, \mathrm{s})$ \\
\hline \multirow[t]{2}{*}{18} & 38.3 & $1.78(1 \mathrm{H}, \mathrm{m})$ & Ac- $4^{\prime}$ & $170.1^{c}$ & \\
\hline & & $1.88(1 \mathrm{H}, \mathrm{m})$ & & $21.1^{d}$ & $1.98^{e}(3 \mathrm{H}, \mathrm{s})$ \\
\hline 19 & 71.4 & $5.22(1 \mathrm{H}, \mathrm{m})$ & Ac- $-5^{\prime}$ & 170.2 & \\
\hline 20 & 131.3 & $5.40(1 \mathrm{H}, \mathrm{dd}, 15.5,7.4)$ & & 21.3 & $2.06(3 \mathrm{H}, \mathrm{s})$ \\
\hline 21 & 128.9 & $5.48(1 \mathrm{H}, \mathrm{dt}, 15.5,7.0)$ & & & \\
\hline
\end{tabular}

[a] Assignments were based on ${ }^{1} \mathrm{H}-{ }^{1} \mathrm{H}$ COSY, HSQC, HMBC, ${ }^{1} \mathrm{H}-{ }^{1} \mathrm{H}$ TOCSY, HSQC-TOCSY experiments.

[b] Recorded in $\mathrm{CDCl}_{3}$. [c] Interchangeable. [d] Interchangeable. [e] Interchangeable. 


\section{Ozonolysis of 3}

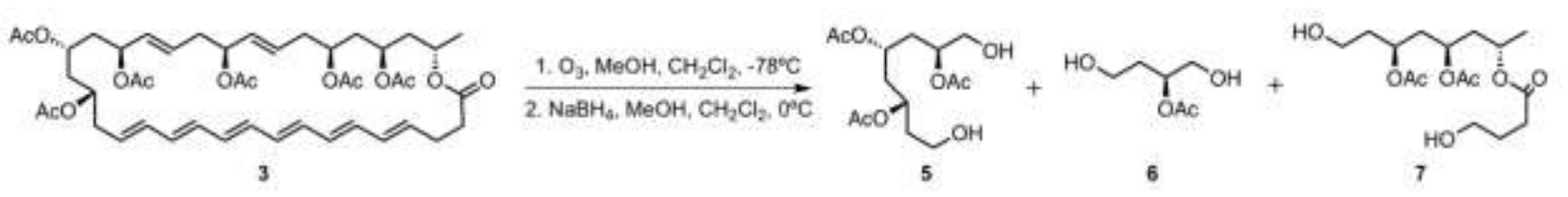

The mixture 3 (44.0 mg) was dissolved in $4.2 \mathrm{~mL} \mathrm{CH}_{2} \mathrm{Cl}_{2} / \mathrm{MeOH}(1: 1)$ and subjected to ozonolysis at $-78^{\circ} \mathrm{C}$ for $35 \mathrm{~min}$. Excess ozone was removed by purging the reaction mixture with $\mathrm{N}_{2}$. To a solution was added excess $\mathrm{NaBH}_{4}(39.7 \mathrm{mg}, 1.06 \mathrm{mmol})$ and stirred on ice for $30 \mathrm{~min}$ and then quenched by adding water. The resulting mixture was extracted with EtOAc, washed with brine, dried over $\mathrm{MgSO}_{4}$ and concentrated to give the mixture of $\mathbf{5 , 6}$ and $\mathbf{7}(33.0 \mathrm{mg})$.

\section{Synthesis and isolation of the fragment 12}

The mixture of $\mathbf{5}, 6$ and $7(7.6 \mathrm{mg})$ was dissolved in $200 \mu \mathrm{L}$ pyridine and $\mathrm{Ac}_{2} \mathrm{O}(100 \mu \mathrm{L}, 1.06 \mathrm{mmol})$ at room temperature for 11 hours and then concentrated. The resulting mixture was subjected to flash silica gel column chromatography eluted with $n$-hexane-EtOAc (1/1) to give $\mathbf{1 2}(1.8 \mathrm{mg})$.
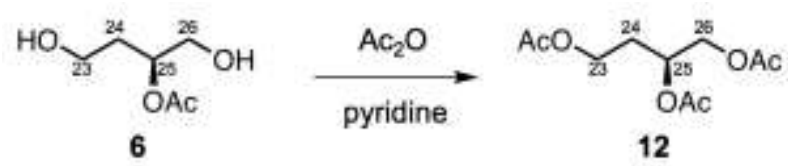

12: HRESIMS: $m / z 427.1574[\mathrm{M}+\mathrm{Na}]^{+} 427.1580$ calcd. for $\left.\mathrm{C}_{18} \mathrm{H}_{28} \mathrm{O}_{10} \mathrm{Na}\right), 1 \mathrm{H} \mathrm{NMR}\left(500 \mathrm{MHz}, \mathrm{CDCl}_{3}\right) ; \delta=$ 5.19 (m, H-25), 4.28 (dd, 12.0, 3.5, Ha-26), 4.13 (t, 6.3, H-23), 4.07 (dd, 12.0, 6.0, Hb-26), 2.07 (s, 3H x 2), 2.05 (s, 3H), 1.95 (m, H-24).

\section{Synthesis of authentic $(S)-12$ and $(R)-12$}

(R)-1,2,4-butanetriol (TCI B3137) (2.3 mg) or (S)-1,2,4-butanetriol (TCI B2404) (1.3 mg) was dissolved in $100 \mu \mathrm{L}$ pyridine and $\mathrm{Ac}_{2} \mathrm{O}(50 \mu \mathrm{L}, 0.53 \mathrm{mmol})$ at room temperature for 12 hours and then concentrated. The reactions proceeded spot to spot and the resulting mixtures were evaporated to give $(R)-\mathbf{1 2}(2.3 \mathrm{mg})$ and (S)-12 (1.9 mg), respectively. The purities of both authentic samples were confirmed by their ${ }^{1} \mathrm{H}$ NMR spectra.

\section{VCD Spectroscopy}

VCD and IR spectra were recorded on a JASCO FVS-6000 spectrometer using an optical filter that passes through 2200-850 $\mathrm{cm}^{-1}$ light and a MCT-V detector. VCD and IR data were acquired for 2000 and 16 scans, respectively, at a resolution of $8 \mathrm{~cm}^{-1}$ at ambient temperature. A 50- $\mu \mathrm{m} \mathrm{BaF}_{2}$ cell (JASCO) was used. All the spectra were corrected by solvent spectra obtained under the identical measurement conditions, and presented as $\Delta \varepsilon$ and $\varepsilon$ (both in $\mathrm{M}^{-1} \mathrm{~cm}^{-1}$ ). 


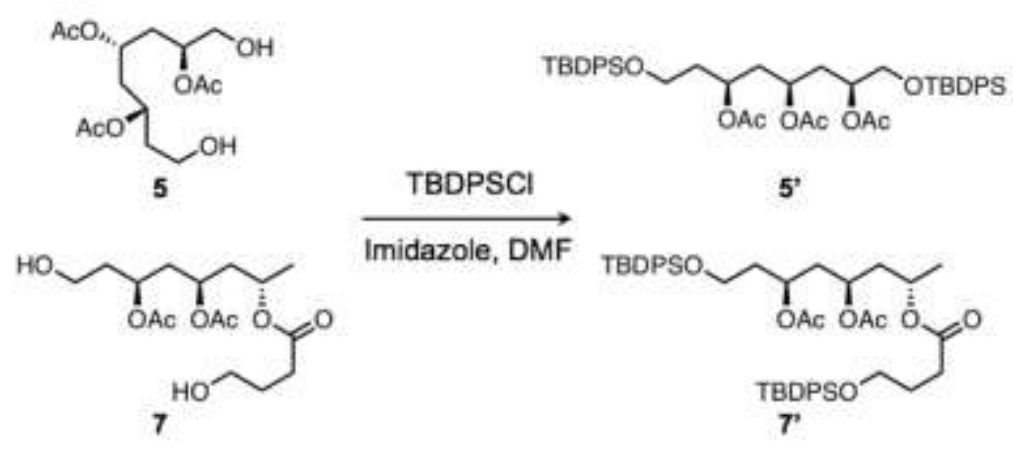

The mixture of $\mathbf{5}, \mathbf{6}$ and $\mathbf{7}(23.9 \mathrm{mg})$ was separated roughly by silica gel column chromatography eluted with $\mathrm{CHCl}_{3}-\mathrm{MeOH}(40 / 1-19 / 1)$ to give mixture of 5 and 7 (17.1 mg). The mixture (17.1 mg) and imidazole (56.9 mg, $831.4 \mu \mathrm{mol})$ were dissolved in $800 \mu \mathrm{L} \mathrm{DMF}$ on ice. TBDPS chloride $(71.2 \mu \mathrm{L}, 277.3 \mu \mathrm{mol})$ was added to the cooled solution and after the addition was complete the ice bath was removed, and the reaction was stirred for $24 \mathrm{~h}$ at room temperature. To the reaction mixture was added water and extracted with a mixed solvent ( $n$-hexane/EtOAc=1/1), washed with water, brine and concentrated. LC-MS analysis of the extract showed the presence of $\mathbf{5}^{\prime}\left(\mathrm{m} / z 819[\mathrm{M}+\mathrm{Na}]^{+}\right)$and $\mathbf{7}^{\prime}\left(\mathrm{m} / \mathrm{z} 847[\mathrm{M}+\mathrm{Na}]^{+}\right)$. The mixture was subjected to silica gel column chromatography eluted with $n$-hexane-EtOAc (19/1-12/1-6/1) to give the mixture of 5'and 7' (12.1 mg)

\section{Methanolysis of the fragments $5^{\prime}$ and $7^{\prime}$}
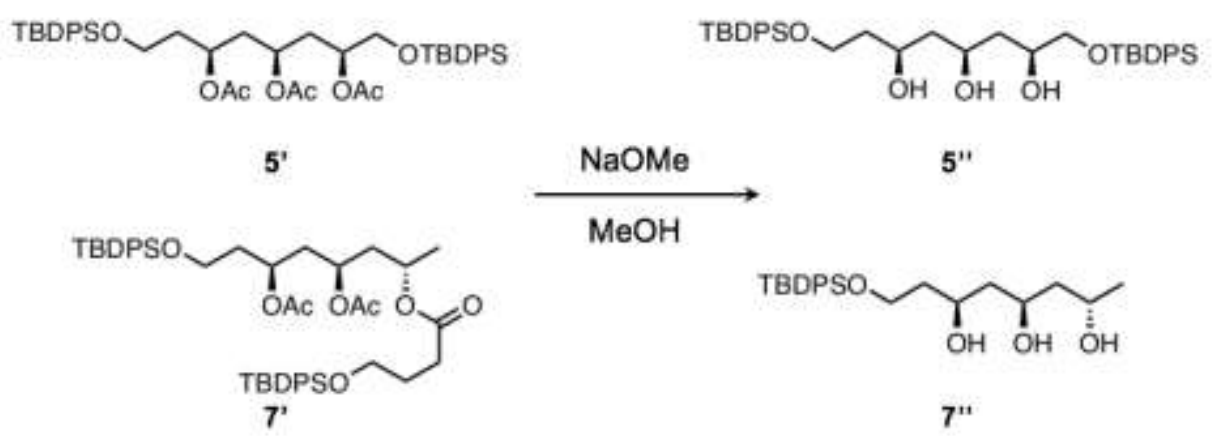

The mixture of $5^{\prime}$ and $7^{\prime}(12.1 \mathrm{mg})$ was dissolved in $600 \mu \mathrm{L} \mathrm{MeOH}$ and added $1 \mathrm{M} \mathrm{NaOMe}$ solution (c.a. $360 \mu \mathrm{L}$ ). The react was stirred at room temperature for 1.5 hours. The reaction mixture was evaporated and analyzed by LC-MS, showing the presence of 5" $\left(\mathrm{m} / \mathrm{z} 733[\mathrm{M}+\mathrm{Na}]^{+}\right)$and $\mathbf{7}^{\prime \prime}\left(\mathrm{m} / \mathrm{z} 439[\mathrm{M}+\mathrm{Na}]^{+}\right)$. The reaction mixture was repeatedly subjected to flash silica gel column chromatography eluted with EtOAc- $\mathrm{MeOH}(9 / 1)$ and $\mathrm{CHCl}_{3}-\mathrm{MeOH}(80 / 1-40 / 1)$ to give rough 5" $(5.5 \mathrm{mg})$ and pure 7" $(1.6 \mathrm{mg})$. 


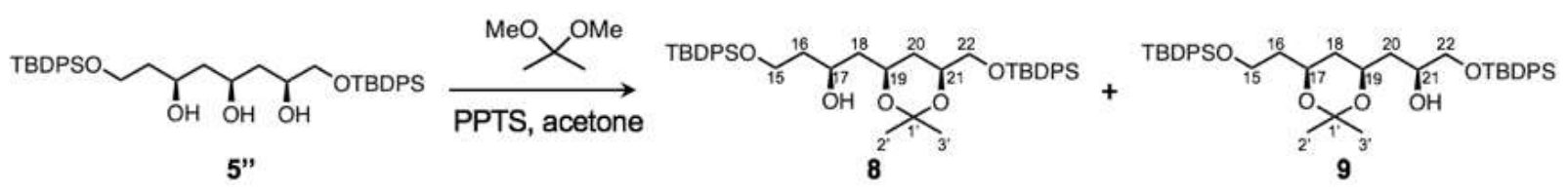

To a solution of rough $5^{\prime \prime}(5.5 \mathrm{mg})$ and three particles of pyridinium $p$-toluenesulfonate (PPTS) in $250 \mu \mathrm{L}$ dry acetone, 2,2-dimethoxypropane (DMP) $(20.8 \mu \mathrm{L}, 170 \mu \mathrm{mol})$ was added on ice and stirred for 1.5 hours at room temperature and then quenched by adding saturated sodium bicarbonate solution. The resulting mixture was extracted with EtOAc and concentrated. The mixture $(5.1 \mathrm{mg})$ was subjected to a flash silica gel column chromatography eluted with $n$-hexane-EtOAc $(6 / 1)$ to give $\mathbf{8}(0.8 \mathrm{mg})$ and $\mathbf{9}(0.5 \mathrm{mg})$.

To confirm the planal structures, all their proton signals were assigned by the chemical shift and the COSY correlation. The relative configurations were identified based on the selected NOESY correlations. The syn conformation at C-19 and C-21 in $\mathbf{8}$ was confirmed by a series of NOESY correlations of $\mathrm{H}-21 / \mathrm{H}_{3}-2^{\prime}$, Ha-20 and $\mathrm{H}-19 / \mathrm{H}_{3}-2^{\prime}, \mathrm{Ha}-20$, as well as the syn relationship at C-17 and $\mathrm{C}-19$ in 9 by the correlations of $\mathrm{H}-19 / \mathrm{H}_{3}-2^{\prime}$ Ha-18 and $\mathrm{H}-17 / \mathrm{H}_{3}-2^{\prime}$, Ha-18. Therefore, the relative configurations were decided as (17,19)-syn and (19,21)-syn conformation in $\mathbf{1}$ (see Figure 3B).

Compound 8: HRESIMS: $m / z 733.3699[\mathrm{M}+\mathrm{Na}]^{+}\left(733.3715\right.$ calcd. for $\left.\mathrm{C}_{43} \mathrm{H}_{58} \mathrm{O}_{5} \mathrm{NaSi}_{2}\right), 1 \mathrm{H}$ NMR (800 $\mathrm{MHz}, \mathrm{CDCl}_{3}$ ); $\delta=4.10$ (m, H-19), 4.03 (m, H-17), 3.99 (m, H-21), 3.85 (m, Ha-15), 3.81 (m, Hb-15), 3.71 (dd, 10.4, 4.8, Ha-22), 3.59 (brs, 17-OH), 3.54 (dd, 9.6, 5.6, Hb-22), 1.75 (m, Ha-16), 1.66 (m, Hb-16), 1.66 (m, Ha-18), 1.62 (m, Ha-20), 1.58 (m, Hb-18), 1.44 (s, $\mathrm{H}_{3}-2^{\prime}$ ), 1.35 (s, $\mathrm{H}_{3}-3^{\prime}$ ), 1.21 (m, Hb-20).

Compound 9: HRESIMS: $\mathrm{m} / z$ 733.3702 $[\mathrm{M}+\mathrm{Na}]^{+}$(733.3715 calcd. for $\mathrm{C}_{43} \mathrm{H}_{58} \mathrm{O}_{5} \mathrm{NaSi}_{2}$ ), $1 \mathrm{H}$ NMR (800 $\mathrm{MHz}, \mathrm{CDCl}_{3}$ ); $\delta=4.11$ (m, H-17), 4.03 (m, H-19), 3.91 (m, H-21), 3.83 (m, Ha-15), 3.68 (m, Hb-15), 3.62 (dd, 10.2, 6.1, Ha-22), 3.57 (dd, 10.0, 5.1, Hb-22), 3.16 (brd, 17-OH), 1.69 (m, Ha-16), 1.66 (m, Hb-16),

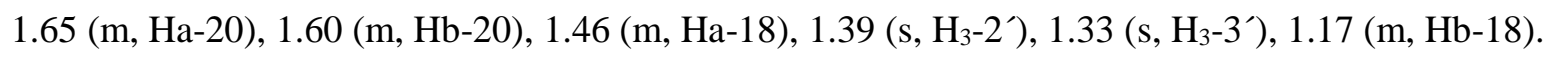




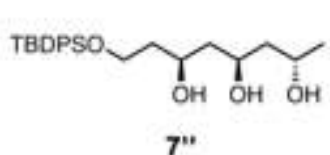

7"

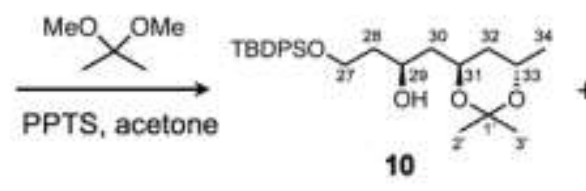

10

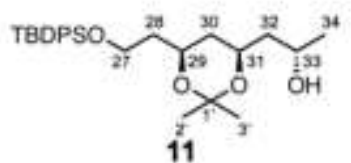

To a solution of 7" (1.6 mg) and two particles of PPTS in $80 \mu \mathrm{L}$ dry acetone, 2,2-DMP (9.4 $\mu \mathrm{L}, 77 \mu \mathrm{mol})$ was added on ice and stirred for 1.5 hours at room temperature and then quenched by adding saturated sodium bicarbonate solution. The resulting mixture was extracted with EtOAc and concentrated. The mixture $(1.5 \mathrm{mg})$ was subjected to a flash silica gel column chromatography eluted with $n$-hexane-EtOAc (12/1) to give $10(0.5 \mathrm{mg})$ and $\mathbf{1 1}(0.7 \mathrm{mg})$.

To confirm the planal structures, all their proton signals were assigned by the chemical shift and the COSY correlation. The anti-relationship at C-31 and C-33 in $\mathbf{1 0}$ was identified by the NOESY correlations of $\mathrm{H}-31 / \mathrm{H}_{3}-2^{\prime}, \mathrm{Hb}-32$, and $\mathrm{H}-33 / \mathrm{H}_{3}-3^{\prime}, \mathrm{Ha}-32$. Each signal from methyl protons to distinct methylene protons at C-3 suggested that $\mathbf{1 0}$ took a twist boat conformation. The syn relationship at C-29 and C-31 in $\mathbf{1 1}$ was also decided by the NOESY correlations of H-29/ $\mathrm{H}_{3}-2^{\prime}$, Ha-30 and $\mathrm{H}-31 / \mathrm{H}_{3}-2^{\prime}, \mathrm{Ha}-30$. Therefore, the relative configurations were decided as (29,31)-syn and (31,33)-anti relationship in $\mathbf{1}$ (see Figure 3B).

Compound 10: HRESIMS: $m / z 479.2594[\mathrm{M}+\mathrm{Na}]^{+}\left(479.2588\right.$ calcd. for $\left.\mathrm{C}_{27} \mathrm{H}_{40} \mathrm{O}_{4} \mathrm{NaSi}\right),{ }^{1} \mathrm{H}$ NMR $(800$ $\mathrm{MHz}, \mathrm{CDCl}_{3}+20 \% \mathrm{C}_{6} \mathrm{D}_{6}$ ); 4.00 (m, H-31), 3.98 (m, H-29), 3.91 (m, H-33), 3.83 (m, Ha-27), 3.80 (m, Hb-27), 3.55 (brs, 29-OH), 1.73 (m, Ha-28), 1.64 (m, Hb-28), 1.57 (m, Ha-32), 1.54 (m, Hb-30), 1.51 (m, Hb-32), $1.36\left(\mathrm{~s}, \mathrm{H}_{3}-2^{\prime}\right), 1.32$ ( $\left.\mathrm{s}, \mathrm{H}_{3}-3^{\prime}\right), 1.16$ (d, 5.6, $\left.\mathrm{H}_{3}-34\right)$.

Compound 11: HRESIMS: $\mathrm{m} / z$ 479.2590 $[\mathrm{M}+\mathrm{Na}]^{+}$(479.2588 calcd. for $\mathrm{C}_{27} \mathrm{H}_{40} \mathrm{O}_{4} \mathrm{NaSi}$ ), $1 \mathrm{H}$ NMR (800 $\mathrm{MHz}, \mathrm{CDCl}_{3}$ ); $\delta=4.18$ (m, H-31), 4.15 (m, H-29), 4.08 (m, H-33), 3.84 (m, Ha-27), 3.69 (m, Hb-27), 2.77 (brd, 33-OH), 1.71 (m, Ha-28), 1.68 (m, Hb-28), 1.60 (m, H2-32), 1.45 (s, H3-2'), 1.37 (s, H3-3'), 1.36 (m, Ha-30), 1.34 (m, Hb-30), 1.20 (d, 5.6, $\left.\mathrm{H}_{3}-34\right)$. 


\section{Synthesis of $(S)$ - and $(R)$-MTPA esters of 8}

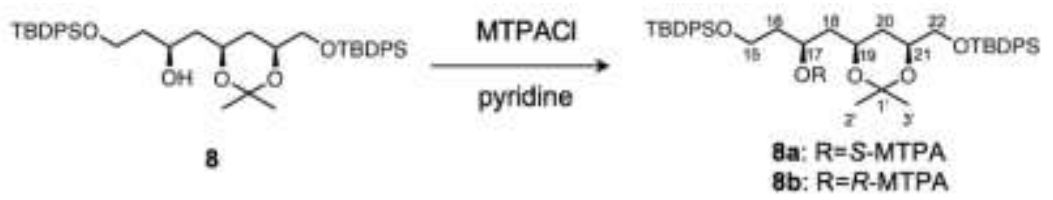

For the preparation of the (S)-MTPA ester, $0.2 \mathrm{mg}$ of 8 was dissolved in $30 \mu \mathrm{L}$ pyridine and $2 \mu \mathrm{L}$ $(R)$-MTPA chloride was added. The mixture was incubated at room temperature for 2 hours and then EtOAc and water were added. The water layer was extracted with EtOAc twice and concentrated. The resulting mixture was separated by PTLC ( $n$-hexane-EtOAc $=6 / 1)$ to give $(S)$-MTPA ester 8a. The $(R)$-MTPA ester $\mathbf{8 b}$ was prepared in the same manner by the addition of $2 \mu \mathrm{L}(S)$-MTPA chloride. The complete assignment of all protons was achieved using ${ }^{1} \mathrm{H}-{ }^{1} \mathrm{H}$ COSY experiment.

Compound 8a: HRESIMS: $m / z$ 949.4116 $[\mathrm{M}+\mathrm{Na}]^{+} 949.4113$ calcd. for $\left.\mathrm{C}_{53} \mathrm{H}_{65} \mathrm{O}_{7} \mathrm{~F}_{3} \mathrm{NaSi}_{2}\right), 1 \mathrm{H}$ NMR $(800$ $\mathrm{MHz}, \mathrm{CDCl}_{3}$ ); $\delta=5.52$ (m, H-17), 3.91 (m, H-19), 3.90 (m, H-21), 3.69 (dd, 10.4, 5.1, Ha-22), 3.59 (m, Ha-15), 3.56 (m, Hb-15), 3.52 (dd, 10.4, 5.8, Hb-22), 1.92 (m Ha-18), 1.84 (m, Ha-16), 1.82 (m, Hb-16), 1.72 (m, Hb-18), 1.60 (m, Ha-20), 1.14 (m, Hb-20),1.33 (s, $\left.\mathrm{H}_{3}-2^{\prime}\right), 1.31$ (s, $\mathrm{H}_{3}-3^{\prime}$ ).

Compound 8b: HRESIMS: $m / z$ 949.4111 $[\mathrm{M}+\mathrm{Na}]^{+} 949.4113$ calcd. for $\left.\mathrm{C}_{53} \mathrm{H}_{65} \mathrm{O}_{7} \mathrm{~F}_{3} \mathrm{NaSi}_{2}\right), 1 \mathrm{H}$ NMR $(800$ $\mathrm{MHz}, \mathrm{CDCl}_{3}$ ); $\delta=5.47$ (m, H-17), 3.81 (m, H-21), 3.70 (m, Ha-15), 3.68 (m, Hb-15), 3.68 (m, H-19), 3.67 (m, Ha-22), 3.50 (dd, 10.2, 5.8, Hb-22), 1.93 (m, Ha-16), 1.90 (m, Hb-16), 1.84 (m, Ha-18), 1.68 (m, Hb-18), 1.51 (m, Ha-20), 1.06 (m, Hb-20),1.27 (s, $\left.\mathrm{H}_{3}-2^{\prime}\right), 1.20$ (s, $\mathrm{H}_{3}-3^{\prime}$ ).

\section{Synthesis of $(S)$ - and $(R)$-MTPA esters of 10}

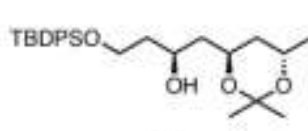

10

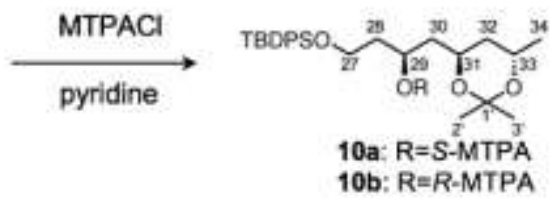

$(S)$-MTPA ester 10a and $(R)$-MTPA ester 10b were prepared in the same manner as described in the synthesis of $\mathbf{8 a}$ and $\mathbf{8 b}$.

Compound 10a: HRESIMS: $m / z$ 695.2966 $[\mathrm{M}+\mathrm{Na}]^{+}\left(695.2986 \mathrm{calcd}\right.$. for $\left.\mathrm{C}_{37} \mathrm{H}_{47} \mathrm{O}_{6} \mathrm{~F}_{3} \mathrm{NaSi}\right),{ }^{1} \mathrm{H}$ NMR $(800$ $\mathrm{MHz}, \mathrm{CDCl}_{3}$ ); $\delta=5.51$ (m, H-29), 3.93 (m, H-33), 3.88 (m, H-31), 3.59 (m, Ha-27), 3.57 (m, Hb-27), 1.95 (ddd, 14.2, 8.0, 6.2, Ha-30), 1.87 (m, Ha-28), 1.83 (m, Hb-28), 1.76 (ddd, 14.2, 5.6, 5.6, Hb-30), 1.60 (m, Ha-32), 1.57 (m, Hb-32), 1.32 (s, $\mathrm{H}_{3}-2^{\prime}$ ), 1.28 (s, $\left.\mathrm{H}_{3}-3^{\prime}\right), 1.18$ (d, 6.2, $\left.\mathrm{H}_{3}-34\right)$.

Compound 10b: HRESIMS: $m / z$ 695.2972 [M+Na] ${ }^{+}$(695.2986 calcd. for $\left.\mathrm{C}_{37} \mathrm{H}_{47} \mathrm{O}_{6} \mathrm{~F}_{3} \mathrm{NaSi}\right),{ }^{1} \mathrm{H}$ NMR $(800$ $\mathrm{MHz}, \mathrm{CDCl}_{3}$ ); $\delta=5.48$ (m, H-29), 3.89 (m, H-33), 3.72 (m, H-31), 3.70 (m, Ha-27), 3.69 (m, Hb-27), 1.92 (ddd, 6.3, 6.3 ,6.3, $\mathrm{H}_{2}-28$ ), 1.88 (ddd, 14.1, 7.4, 7.4, Ha-30), 1.71 (ddd, 14.1, 5.7, 5.7, Hb-30), 1.55 (m, Ha-32), 1.48 (m, Hb-32), 1.29 (s, $\mathrm{H}_{3}-2^{\prime}$ ), 1.20 (s, $\mathrm{H}_{3}-3^{\prime}$ ), 1.16 (d, 6.2, $\mathrm{H}_{3}-34$ ). 


\section{Culture medium for Arthrinium phaeospermum Kemushi-1}

CPS medium: $1.75 \%$ Czapek-Dox Broth, $0.17 \%$ Meat peptone, $0.17 \%$ Soy peptone, $0.17 \%$ Casein peptone, $1.0 \%$ Soluble Starch, $0.5 \%$ Maltose H in $60 \mathrm{~mL}$ Distilled water.

PDB medium: 2.4\% Potato Dextrose Broth in $60 \mathrm{~mL}$ Distilled water.

MYG medium: $0.4 \%$ Yeast extract, $0.4 \%$ D-Glucose in $60 \mathrm{~mL}$ Distilled water.

\section{Cultivation of Arthrinium phaeospermum Kemushi-1 in CPS medium and HPLC analysis}

Arthrinium phaeospermum Kemushi-1 was cultivated on a PDB agar plate at $25^{\circ} \mathrm{C}$ and its mycelia was inoculated in MYG, PDB or CPS medium and incubated at $30^{\circ} \mathrm{C}$ for 5 days. The cultured mycelia were harvested and freeze-dried. The $40 \mathrm{mg}$ of the crushed mycelia was extracted with $1 \mathrm{~mL} \mathrm{MeOH}$ for $30 \mathrm{~min}$. After centrifuged at 13,500 rpm for $15 \mathrm{~min}, 500 \mu \mathrm{L}$ was transferred to a new tube and concentrated under reduced pressure to obtain $\mathrm{MeOH}$ extract. The extract was resuspended with $100 \mu \mathrm{L} \mathrm{MeOH}$, centrifuged again, and $10 \mu \mathrm{L}$ was injected into HPLC. Flow rate; $1 \mathrm{~mL} / \mathrm{min}$, Solvent gradient system: acetonitrile and water with $0.01 \%$ TFA (0-2 min: 20:80, 2-12 $\min$ : 20:80 to 100: 0, 12-24 min: 100:0). Absorbance was monitored at $380 \mathrm{~nm}$.

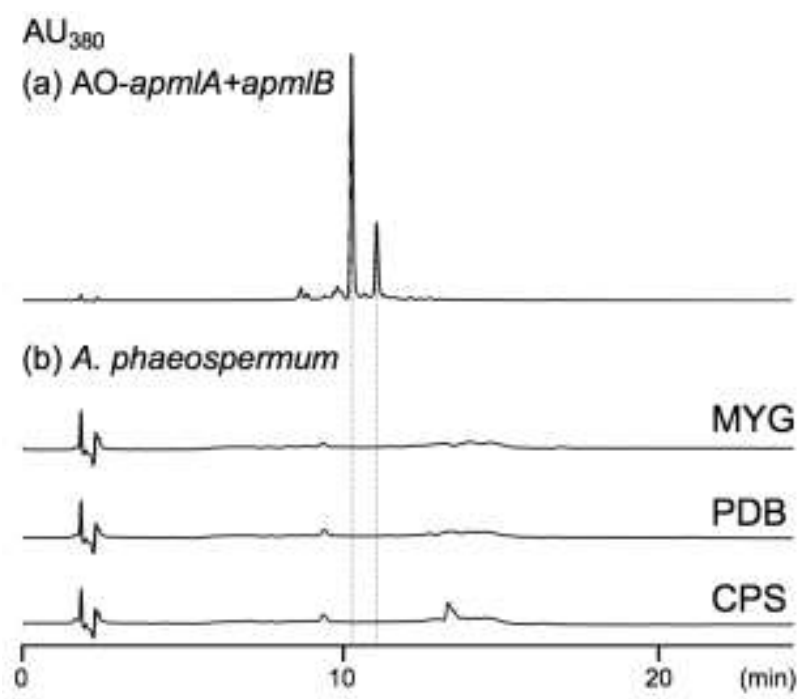

Figure S5. Comparison of HPLC profiles of AO-apmlA+apmlB and A. phaeospermum.

HPLC profiles of mycelial MeOH extracts of AO-apmlA+apmlB in CPS media (a) and A. phaeospermum in some laboratory culture conditions. 


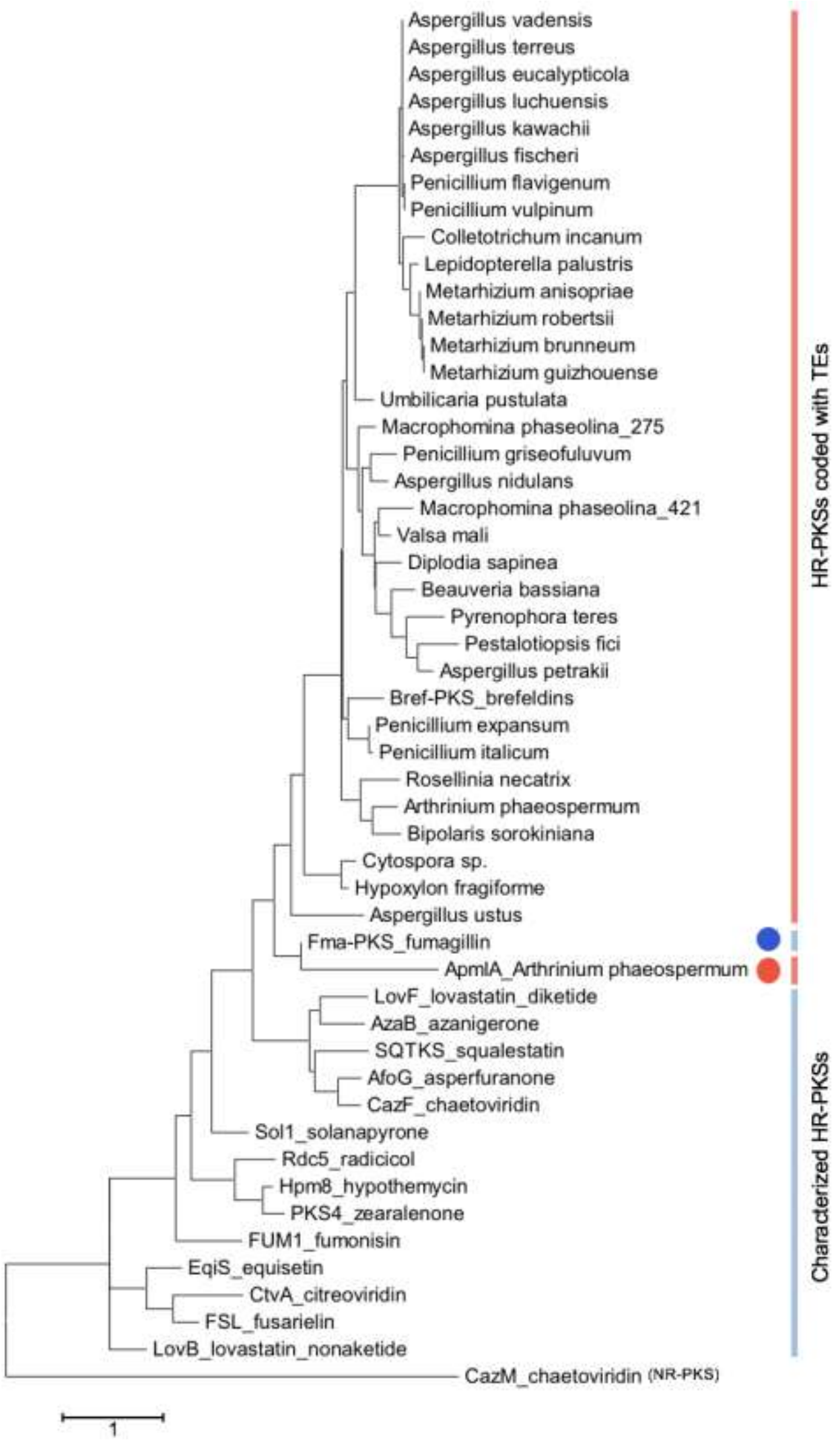

Figure S6. Phylogenetic analysis of DH domains of HR-PKSs.

The HR-PKSs coded with TE and characterized HR-PKSs sequences were aligned with CLUSTALW, and phylogenetic analyses were conducted using MEGA version 7.0.26 by means of the boot strap maximum likelihood method. PT domain of characterized CazM (NR-PKS) was placed as the root of the tree. The DH domain of ApmlA (red circle) is most similar to that of Fma-PKS (blue circle) (37\% identity and 54\% similarity). 


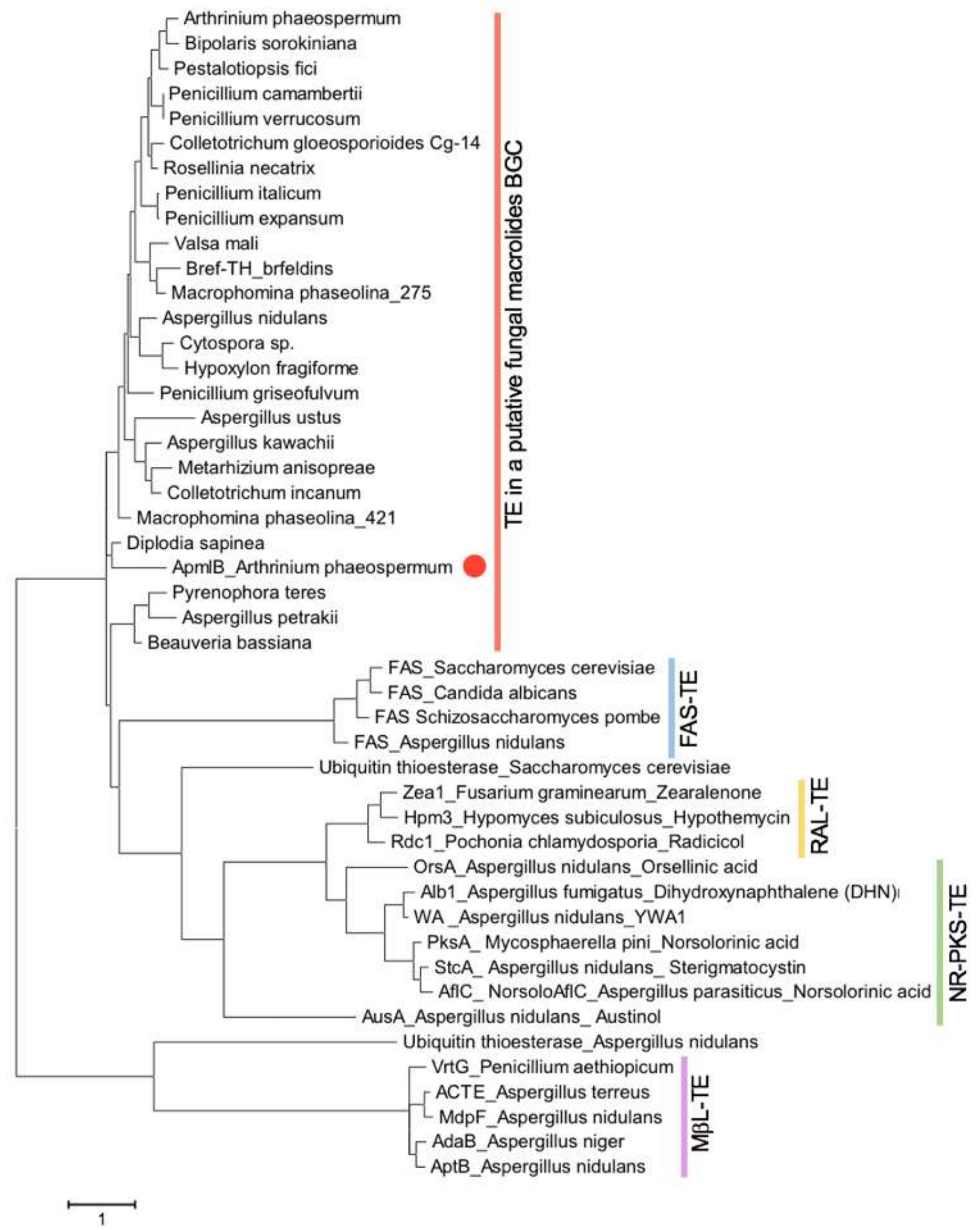

Figure S7. Phylogenetic analysis of ApmlB and selected fungal TEs and TE domains.

The fungal TEs sequences were aligned with CLUSTALW, and phylogenetic analyses were conducted using MEGA version 7.0.26 by means of the boot strap maximum likelihood method. Colored lines indicate functionally similar group: RAL-TE, TE domain of NR-PKS connected with resorcylic acid lactone biosynthesis; NR-PKS-TE, TE domain of NR-PKS that biosynthesize fungal polyketides; FAS-TE, TE domain of fungal fatty acid synthase; M $\beta \mathrm{L}-\mathrm{TE}$, metallo- $\beta$-lactamase-type TE. 


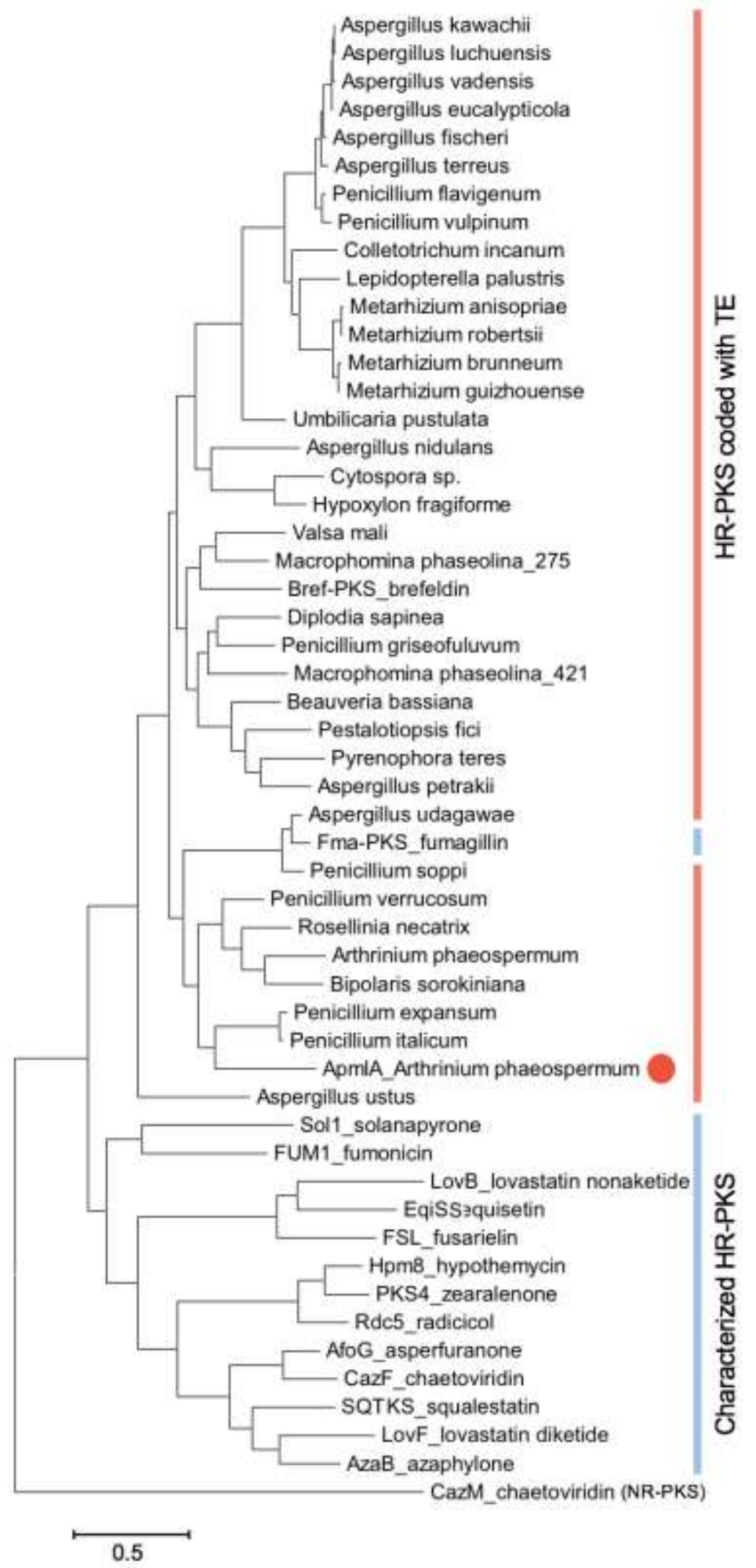

Figure S8. Phylogenetic analysis of fungal HR-PKSs.

The HR-PKSs coded with TE and characterized HR-PKSs sequences were aligned with CLUSTALW, and phylogenetic analyses were conducted using MEGA version 7.0.26 by means of the boot strap maximum likelihood method. Characterized CazM (NR-PKS) was placed as the root of the tree. ApmlA is highlighted with red circle. 
Table S4. apml cluster in a hairy caterpillar-associated fungus, Arthrinium phaeospermum Kemushi-1.

\begin{tabular}{c|c|c|c|c}
\hline Gene name & $\begin{array}{c}\text { Accession } \\
\text { number }\end{array}$ & Size & Protein homologue (accession number) & $\begin{array}{c}\text { identity (\%)/ } \\
\text { similarity (\%) }\end{array}$ \\
\hline apmlA & LC468825 & $7,834 \mathrm{bp}$ & hypothetical protein ACN42_g5244 [Penicillium freii] (KUM61888) & $47 / 64$ \\
apmlB & LC468826 & $977 \mathrm{bp}$ & hypothetical protein BP5796_08380[Coleophoma crateriformis] (RDW69983) & $45 / 61$ \\
\hline
\end{tabular}

apmlA

\section{Nucleotide}

ATGTCGGACCATAACCATACAAACGGCACAACCAACGGGAATGGCATCGGGAGTAACGGAGTCCAGAGCCACGTGCCCAA TGGTGCCCACATCAATGGCACATCCAGCGGCTTGAAGCCCAATGGAATATCAAACGGGACAACTAATGGCATCAATGGCCA CGCACCCTCCACCGCAGCAACACAGACCCCTGTGGCTGTTGTTGGCCTAGCATGCCGCCTTCCGGGGAAAAGCAATTCCC CTGAGGCTCTTTGGAAATTCCTCCTCGACGGTGGTGTGGCCGATCCCACCCCGCCCGATCACCGCTATAACTTCTCGACG CACTATGATGGCTCGCAACGACCGGGCACCATGCCGTCTCCGGGCGGCATGCTCCTCCGCGACGTGGACCTGACGGCTT TTGATGCCTCCTTTTTCAACATTGGCCATGCGGAAGCTGCGGTGATGGACCCGCAGCAGCGTCAACTGCTGGAAGTCACAT ACGAGTGTCTAGAGAACAGTGGTGTTCCCTTGGGAAAGCTCCGGGGGACTAGAGCCGGATGTGTAGTGGCTAATAACGCC GTCGGTGAGTCGCCATTGAGTTATGTTGTATGCCGATCAGGTGACTGACGCGGATGTTCCGCCCCCCTTTTACAGAGTATG AGGGGTTCGCTACTCATGATCGCGAAGATAATGTCAGCGGTGGGAGTACGGGGTTCTCCCGGTCCATCTTGAGTAATCGG ATCTCACATTACCTCGACATCCAGGGTCCAAGGTATGCTCTATTTTGCTTACGGGTGGATAATTCCCGTTTCGGGCGGTCTA TAAACACGAGCTTCATTCTAATTGGACGGCAGTATATCCATTGACACAGCCTGCTCCGGAACTTTGGTCGGTGTCGACCTG GCCTGCCGTTACCTCCAGACCAATCAAGCGGATGGCATGCTGGTCGGAGGTGCCCTGTTGTATCTTGACCCCTCGGCCTT GCAGGACACGGGACCCATGAAGGGCGCCTTCTCTCCTACAGGGCAGTGCCATACCTTCGACGCCGACGCAGATGGATAC ATTCGAGGAGAGGCCATCAGCTGTGTGTACCTCAAGCGCCTAGACGACGCTATCCGGGATGGTGATCCTATTCGAGCCGT CATTCGGGGCAGCGCTACCAACAGTGACGGTAACACCACCAGCCTTACGCAGCCCAGCTCGGCAGCCCAAGCAGCGGCT ATCCGCATGGCATATTCTAATGCTGGTATAAGCGACTTCAATGAGACGGGCTACCTTGAATGCCACGGGACGGGGACGCC TACGGGCGACCCTCTGGAAGTGGCCGGTCTCGCCTCCGTCTTTGCGCCTACCCGGCCCGCCGAGAAGCCCCTGATCATC GGGTCGATCAAGAGCAACGTCGGACACTCGGAGAGTGCGGCTGGTCTGTCGGGCCTGATCAAAACGGTCCTGACGGTGG AGCGAGGCGTCATCCCGGGTACCCCCACATTTATCAAACCCACGCCACGCATCGACTTTGACAAGTCGCGGGTGCGGCCG TCGAGACGCACCATCCGCTGGCCCCAGAGCGCCTCGGGTCTCCGTCGGGCCAGTGTGAACTCGTTTGGGTTCGGCGGCA CCAATGCCCACGTCGTCCTCGAAGCCAGGGACTCGATGATCAAGGACCCCAGCGTCCGCAAGGGCTTTGTCTTCTCCAAC CATGGCTCCAGTCTTTTTGGGCTCGACGCAGACCTGGAGGCTGGCTCGGAGCGGCCCTACATCCTTGCACTCTCGGCCAA TGACAAAGACGCACTGGAAACCAACATTCAGACTTTGTCAACCCACCTTGGCGACCCTGCCGTTGGTGTAAAGCTGAGCGA TGTGGCATACACGCTCTCAGAACGGCGTACGCATCATTTCCACCGCGGATTCGTCATTGCGGACTCCTTGGAAATCTCCTC CGATTCCATGATCCTCGGCAAGAAGAAGGCGCAGCCACCGCGGGTTGCCTTTATCTTTACCGGACAGGGAGCTCAGTGGA GCCAGATGGGACGAGATCTCATCGAGTCTTTCCCCTTGGCCAAGGCAACGATCCAGAAACTGGACGCGGCACTCCAGACT CTCCCTAATCCCCCACAATGGTCTCTCGTCGACGAGCTCTGTGAGGCGAGAGAGGGGGCGGTGCTGCGGCTTCCTGAATT CTCCCAGCCGCTCGTCACCGCGCTGCAGATCGCCCAGTTGACTGTACTCTCCCACTGGGGCATCTCCGCCACCCGAGTTC TGGGCCACTCCTCAGGCGAGATTGCTGCTGCGGTAGCCGCGGGGCTGGTGCGCCCCGAGGAGGCGATCAAGATTGCGTA TCTCCGAGGCCTGGCGGCTAAGTTCCACCAGCCCGACCAGCCCCTGGGCATGCTGGCGGTCGGTGTCTCGGCTGAGGCC GTCGCCCCCTACCTCGAGACCGAACCAACCGTTCAGATCGCTTGCTTCAACAGCCCCACAAGCCTCACTCTCTCAGGCCA GCAGCCCGATCTGGTGCGCGTCTGCGATCGTTTGAAGGCCGATGGCCATTTTGCCCGGATGCTCCAGGTGAACCTTGCCT ACCACTCGGAACACATCCGCAGCATTGCCGAGGAATACCACAGTCTTCTCAAAGAACAGGTTCCCGGCGCCGCCGGCAGC TCTGGGAACAAGAAGGTCACAATGTTCTCGTCTGTGACGGGCAAGCCGATTTCCGAGGCCTACGACGCCTTGGGTCCAGA CTACTGGCGGCAGAACATGGTCAGCCCCGTCAGATTCGCACAGGCGGCGAGCAACATGCTCTCCGGGCCGGAAAGCAGC GAGTTCCTCATCGAGATCGGTCCCGCCGGTGCCCTGGCCGGGCCGGTCGCGCAGGTGATCAAAGCGGCTCCCAGCGCC CGCAACACTCAATACGTGGCGGCGGCCAAGCGTGGGGCTGACACCCTCCTGGCCCTCTATGAGACGGCCGGCAAGCTCT GGGCCAACTCGGGTGTCGTAGACCTGGCGAAGGTGAACGGATACGACGGGCAGGCCAACCTCGTGGTGGACCTTCCCAA CTACCAGTGGAACCACTCGCGGCGTTATTGGCGGGAGTCCCTGTCGGCTAGTGAGTTTCTGCAGAGGCCGTTCCTCAGCC ACGACCTCCTGGGCTCCAAGATTCTCTCGGTCCCGTGGCACAATCCTACCTTCTATCAGGTCATCGAGCTTAGTGACGTCC CCTGGCTGCGCGACCACAAGATTGGCGACCAGGTCATCTTCCCTGCTGCCGGCTATTTGTCCATGGCGGTGGAGGCTATT CACCAGACCACCGTCATGACACAGTGGAGGGAAAAGGGGGTGCCCAAGTCCTTCGCGTACTGCCTGAAGGATGTGCGTTT CCTCCGAAGTCTGGTACTTGAGGAGGACGTGAGAGCAAAGATCAGCCTGGCCCTGATCCCCCTCCATGCCTCGCCGCGCC GATGGTACAACTTCCGCGTCCGGTCCCTGATGGAGGGCGTCTGGGTGGACCACTGCGACGGCCTGGTCCGCATCGACGA GGAGGCGTTCGACACCACGGCGCCGTCCCGTGCACTGGAACCCCTGGCGCACCCGGAGCCCGGCGCAGTGGGCTACAA GAGCGCCAATGCAGGCGAGTTCTCCTTTGGGCCCGCGTTCCAGCGCATCGAGTACTTCGACTGGATCTGGGGCAGCCCC GAAACCCGCGCCCAGGTCACGACCGAGTACCCCGTCTCCGCCTACTCCAAGCAGTCGGAGTACCCGGTCCATCCTGTCG CTATGGACTGCCTCCTCCAGCTCACGGGCTACTCCATCGCGCAGATGCAGATGAACGCCCTGGACGACATCAACTGCGTG CCCGTCGGCATCGAGGGCATCGTCATCCCCTCCAGGAGCAACCCGCCGGCCAAGTCGTGCATGGTCCGCTCGGTCGCGC ACCTGCTGGATTCGAGCACGAGCCAGACCTACGGTAGTCGCTTTGCCTCGGCGGGACTGTATGACCCGGAGGATCGGAG CTTGGTGATGGAGATCAAGCGGATCCGCTTCGATCCTATCTCTTCGAGAGGAGACCAGTCTGAACACGTCTACATGCACTT TGGCTGGAACGCCGACGTGTCGCTGACGGATGCCGAGGGCTTGAATTCCTACTTGGCTGCAGCAGCAGGATCTCCTGAAG AGAAAGATCTGGTTGCAGTGGCGACGCCGGAGGAACAGAAGAACGATGAGTCGCGTTCTTCTCCTTTTGCTCTTGTGCAAA GGCTCCTGGATGCGCTTGCCCACAGGAGGCCCGAGATGGCCGTGCTGGAGGCCAATCTTGACAGCGATGACAGTACGTG CCTATGGCTGGACCTGCCGAGCAAGTCTAATAACTCTGGGCCTCGGAGCGGGTACAGCAAGTTTCACTGCGTATCTAAAGA CCCCAAGGCCTTGTCCCATCTGCAAGAGACGCACAACGAGGCCCCTCGCACGACATGGGACCTTGTTGACATGGCCCATC 
CCTCGGGTCGTATCGATTCTACTGATAAATTCGACCTCATCTTGGTCAAGTCCTCGGATCCAGAGACGACATTCACTACCCC TGCTCTTCTCTCCAATATTGTAGCATCGGTGTCAGAAGGCGGGATGGTCATCTTGCTCAATACACAGGGCAAGCCGACTGT TTTCCATGACGCATCCCAAGCGCTCGAGGCTTCCGGCCTCTGTCGGACCAAGGATCTGTCTGCATCCGTGGGTGGGCTTG CCATTGTTGCAACAGCTCGCCGGGTTGGCCCAGCGGCCACCACTGCATCTGGAGACAAGGTAATCACCTGCTTCCGGCTC ACAGATGACGATGGACCATCCAATGTCTTGGCAGGCCTCAAAGATGCAGGCTGGGCTGTCAACACATGCAGTGACGCCGA TGCTCTTGCGCACCGCAGCAACATTCTTGTTGTGGATGAGCTGTTCACGACGGTGGCGAGCCGTGTTACGGCTGAACAGT GGAAAATGCTACAGACCATCATCCGGAAAGAGTGCAACGTCCTCTGGGTCACCAAAGGCGGCCAGATGGAGGTGACTGAG CCCGACAGGGCCGCGGCCCCTGGCTTGCTCCGAACGATCCGATCCGAGGAGCTGGGAATCCGTCTCATCTCCCTCGACG TGGAGAACCCGACCGGCCCTCGGACACTCTATGCCATCGAGGAGTGCCTGCGTCTTCTTCAGGAGTCGCACGCCGGGAT CCAGAAAGACAGCGAGTTCGTCGAGAGGGGCGGCGTTATCTTTACGCCGCGCCTCCTGGCCGACCCGGCTTTGAACGCG GCCAAGCACGAACCCGTCAATGGGAGGAAACCCCAAATGGAGAGCCTACAGGATAAGAAAACGCCGGTCTGTCTCGGCGT GGAGCGTGTCGGCACCATTGATTCGCTGCACTACGCGGAGCGGTCCCCGACCCCGCTGCCCATCAAGGACGGCTACATC GAGATCGAGATCCACGCGGCCGGCGTCAACTTCAAGGACCTCGCGTTGACCCTGGGCATCGTGAACAGCAACGACCCGTT CACGCTCGGCGGCGAGGCGGCCGGCGTCGTGTCTCGTATTGGAAAGGGCGTGCCGGGCGACCGGTTCGTGGCTGGTCA GCGCGTGGTAGCCATGTTCCCTGGCAGCTTCGGCAACCGGATCCAGGTGCCCTGGCAGGTCGCGCACGCCATCCCCGAC CGCCTCAGTTTCGAAGAGGCGGCGACGCTGCCCGTGGCTTTCCTCACGGCAATGCACGGGCTTTTCGATCTGGGCAACCT GCAGGCAGGGCAGCGGGTTCTCATCCACTCGGCGACGGGTGGTACGGGCAGCGCGGCGGTGCAGCTTTGCCAACACAT GGGGGCCGAGGTAAGTTTGCACACGAGTTTCGCTTCGAAATGCGCTCAACTAACAACTAACTCTTCTTGGAAAAGATCTTT GCGACCGCTGGCACGGAGGAGAAACGCCGGTTTCTGCAGGACATCTACAACATCCCGGCGGACCACATTTTCTCCTCCCG CACGACCGATTTCGAGCACCAAATCATGCGACTTACCGGCGGGCTGGGCGTCGACGTCATCCTGAACTCGCTGACGGGC GACCTGCTCGAGGCGTCGTGGAACATCATCGCGCACGGCGGCACCATGGTGGAGATTGGCAAGAAGGACATCATGGAGC ACAGCCGCCTGTCCATGGAGCCGTTCAGTCGAAGCGCCTCATTCCGGGCTTTGGACCTGTCGCTGGACACAGCGGATTTG TATGGAAAAGGGGCTGGGTTGGGTCAGACTGTGGGACGGTATGTTTTATGTTTGCCTCTATTTGCATTGATCGATCGCCAC GATCCCGGTTGCTAACCCTGTGTTATGTCCCAGACTCTTTGAACGCCTGTTTTCCCTCCTTGAACGAGGCCACGTCCGCCC GATCACGCCGATGCAGACATTTGCTTTCGGCCAGGTGACGGATGCGCTGGCGCTTATGCGGTCTACCAAGCATATGGGCA AGCTGGTGCTTTCGCGTGGCCCCGATAGCAATGATCAAGTAGCAGTAAGTGACCCAGCACGGGGTTGAGTACTTAACATAA AGGAGACTGACCCATTTTCGTAGATTCGCCCAGCCCAGAGACTCGTTCGGTTCCGACCCGATGCCACCTACCTGCTGGTC GGAGGACTCAAGGGCATCTGCGGCAGTCTCGCCGTGGACTTTGCCAAGAAGGGCGCGAAGCACCTCGCCGCGCTTTCGC GCAGCAATTACGACGACCCGCAGTCGCAGATTGTCCTGCGCCAGCTCAAGGATCTGGACTGCCAGATCGACCTGCTCCGC GGGGACATTACCAAGGTGGAGGATGTGAGGAGGGTGTTCGCAGAGACCACCGTCCCCGTCGCCGGAATCATCCAAGGCG CCATGGTGCTCAGGGTACGTATTAATGGCCATCCAGTGCTGGCTCCCCCACGGACTTGCTGTACGGATATCGACTAACATG ATATGCTTTTAGGATCGTCCCTTTGCCAACATGACGGTGGAAGAGTACCACGCAGCGGCCGCGTGCAAGATCCAAGGCAC CTGGAACCTGCACAACTGCGCGCAGGAGGCGCAGGCGCCCCTCGATTTCTTCACCATCCTGTCGAGCATCTCGAGCGTGC TCGGCAACCCGGCGCAGGGCAACTACGCCTCCGGCTGCTCGTTCCAGGACGCCTTCTCGAGCTACCGCCAGGAGCTCGG CCTGCCGGCCTCGACCGTCAACTTGGGCATCATCGAGCAGATCGGCTACATGGCCCGCAACGAGGACCTGCTGGAGAAG AACGTCAGCAGCGAGGTCGCCAAGGGGATTAATGAGCGCCTGCTGTGCAAGATTATTGGGTACTCGATCCTGCAGCAGAG TGGAAGTCCGGTCAGTGAGGATCCATATAGTCGGGCGCGCATGGTGACGGGCTTGACTATGCCGCAGCCGCCTGACTCG ATGCTGCGGCTGGACGCGCGGTTCGCGGCCCTCTTCGTGCGGGACGGGTCGTCCAGCAACACACAGGCGGGCGGTAGC GGCGCGGCGTCCCAGGACGTCTCGCAGGAGATCAAGGAGCTTAACTTGTTGTTGCGGTCCAAGAGCGCCCGGGCGGCCA ACCTGCCGCAGGTCGTGGATGCGACCCTTGCCGTCGTCAGCGGCTACCTTGTCCGCGCCATGCGGCTGAGCGAGGCCAT TGAGCCCGAGCGGTCCCTCTCGGCCTACGGCATCGATTCGCTGGCTGCCGTCGAGTTCCGGAACTGGCTGAGGCTCGAG CTCGGCGCGGCTATGTCCGTTATTGATATTACGACGGCGCCGTCGCTGCTTTTCTTGGCGGAGAAGATTATTACCAAGGTT GATGGCGTGGAGTAG

\section{Amino acid}

MSDHNHTNGTTNGNGIGSNGVQSHVPNGAHINGTSSGLKPNGISNGTTNGINGHAPSTAATQTPVAVVGLACRLPGKSNSPEAL WKFLLDGGVADPTPPDHRYNFSTHYDGSQRPGTMPSPGGMLLRDVDLTAFDASFFNIGHAEAAVMDPQQRQLLEVTYECLENS GVPLGKLRGTRAGCVVANNAVEYEGFATHDREDNVSGGSTGFSRSILSNRISHYLDIQGPSISIDTACSGTLVGVDLACRYLQTN QADGMLVGGALLYLDPSALQDTGPMKGAFSPTGQCHTFDADADGYIRGEAISCVYLKRLDDAIRDGDPIRAVIRGSATNSDGNTT SLTQPSSAAQAAAIRMAYSNAGISDFNETGYLECHGTGTPTGDPLEVAGLASVFAPTRPAEKPLIIGSIKSNVGHSESAAGLSGLIK TVLTVERGVIPGTPTFIKPTPRIDFDKSRVRPSRRTIRWPQSASGLRRASVNSFGFGGTNAHVVLEARDSMIKDPSVRKGFVFSN HGSSLFGLDADLEAGSERPYILALSANDKDALETNIQTLSTHLGDPAVGVKLSDVAYTLSERRTHHFHRGFVIADSLEISSDSMILG KKKAQPPRVAFIFTGQGAQWSQMGRDLIESFPLAKATIQKLDAALQTLPNPPQWSLVDELCEAREGAVLRLPEFSQPLVTALQIA QLTVLSHWGISATRVLGHSSGEIAAAVAAGLVRPEEAIKIAYLRGLAAKFHQPDQPLGMLAVGVSAEAVAPYLETEPTVQIACFNS PTSLTLSGQQPDLVRVCDRLKADGHFARMLQVNLAYHSEHIRSIAEEYHSLLKEQVPGAAGSSGNKKVTMFSSVTGKPISEAYDA LGPDYWRQNMVSPVRFAQAASNMLSGPESSEFLIEIGPAGALAGPVAQVIKAAPSARNTQYVAAAKRGADTLLALYETAGKLWA NSGVVDLAKVNGYDGQANLVVDLPNYQWNHSRRYWRESLSASEFLQRPFLSHDLLGSKILSVPWHNPTFYQVIELSDVPWLRD HKIGDQVIFPAAGYLSMAVEAIHQTTVMTQWREKGVPKSFAYCLKDVRFLRSLVLEEDVRAKISLALIPLHASPRRWYNFRVRSLM EGVWVDHCDGLVRIDEEAFDTTAPSRALEPLAHPEPGAVGYKSANAGEFSFGPAFQRIEYFDWIWGSPETRAQVTTEYPVSAYS KQSEYPVHPVAMDCLLQLTGYSIAQMQMNALDDINCVPVGIEGIVIPSRSNPPAKSCMVRSVAHLLDSSTSQTYGSRFASAGLYD PEDRSLVMEIKRIRFDPISSRGDQSEHVYMHFGWNADVSLTDAEGLNSYLAAAAGSPEEKDLVAVATPEEQKNDESRSSPFALV QRLLDALAHRRPEMAVLEANLDSDDSTCLWLDLPSKSNNSGPRSGYSKFHCVSKDPKALSHLQETHNEAPRTTWDLVDMAHPS GRIDSTDKFDLILVKSSDPETTFTTPALLSNIVASVSEGGMVILLNTQGKPTVFHDASQALEASGLCRTKDLSASVGGLAIVATARR VGPAATTASGDKVITCFRLTDDDGPSNVLAGLKDAGWAVNTCSDADALAHRSNILVVDELFTTVASRVTAEQWKMLQTIIRKECN VLWVTKGGQMEVTEPDRAAAPGLLRTIRSEELGIRLISLDVENPTGPRTLYAIEECLRLLQESHAGIQKDSEFVERGGVIFTPRLLA DPALNAAKHEPVNGRKPQMESLQDKKTPVCLGVERVGTIDSLHYAERSPTPLPIKDGYIEIEIHAAGVNFKDLALTLGIVNSNDPFT LGGEAAGVVSRIGKGVPGDRFVAGQRVVAMFPGSFGNRIQVPWQVAHAIPDRLSFEEAATLPVAFLTAMHGLFDLGNLQAGQR VLIHSATGGTGSAAVQLCQHMGAEIFATAGTEEKRRFLQDIYNIPADHIFSSRTTDFEHQIMRLTGGLGVDVILNSLTGDLLEASWN IIAHGGTMVEIGKKDIMEHSRLSMEPFSRSASFRALDLSLDTADLYGKGAGLGQTVGRLFERLFSLLERGHVRPITPMQTFAFGQV TDALALMRSTKHMGKLVLSRGPDSNDQVAIRPAQRLVRFRPDATYLLVGGLKGICGSLAVDFAKKGAKHLAALSRSNYDDPQSQI

$$
\text { SI-21 }
$$


VLRQLKDLDCQIDLLRGDITKVEDVRRVFAETTVPVAGIIQGAMVLRDRPFANMTVEEYHAAAACKIQGTWNLHNCAQEAQAPLD FFTILSSISSVLGNPAQGNYASGCSFQDAFSSYRQELGLPASTVNLGIIEQIGYMARNEDLLEKNVSSEVAKGINERLLCKIIGYSIL QQSGSPVSEDPYSRARMVTGLTMPQPPDSMLRLDARFAALFVRDGSSSNTQAGGSGAASQDVSQEIKELNLLLRSKSARAANL PQVVDATLAVVSGYLVRAMRLSEAIEPERSLSAYGIDSLAAVEFRNWLRLELGAAMSVIDITTAPSLLFLAEKIITKVDGVE

apmlB

\section{Nucleotide}

ATGGGTTTGAGTGAGAAGGTCGAGTTTAAGACCCTGGACGGCTTGGTCCTAAGGGGTTTTCTGTACAGCGCCAGGGCGAA AGGGCCAGCAATTGTGATGACTCCAGGGGTAAGTTTGCTCTCTTTTGACACGCCGCTTAGGTTCTAACTAACGCTGGTCAG TTCAATTTCCCTGTTAGTCTGTTATATCACGAGGTCGCGCTTGGTTTCCAGGCGGCAGGCATCACGGCGCTTGTCTACGAC CCCAGGTCCGTTGGGCGAAGCGACGGCCTACCGCGCTCCGATATCAACCCGGCCAAGCAATCCGAAGACTTCAGCGACG CCATCACGTTCCTCAAGACCAAGCCCGTGGTCGACCCGAAGCGCATCGCGCTCTGGGGATACTCGTTGTCGGCGGCCGC CGCGCTGATGGCGGCGGGCCTAGACCCCCGTGTCAAGCTGGTGGTTGCTGTGTGCCCCGCGCCCGTGCCGTACAACTTC GAGGCCCCGGGCAAGAGACGGAAGTACCTAGACCTGGCGATCCGCGACCGCGAGTCGCAAGCCCGAGGGAAGGAGCCG TTCTACGTCCAGTACATCGGCGACTCGGAAGAGACGGCCCTGTTTGACTACCGCAAGCAGCGAGGCATGGAAGAGCTCGA GTACGACGAGGTCGTCGAGAACCTGACCAAGATCGCGCCTGGGTTCCGAAACGAGGTGACTATCCAGACTCTCCGGCGC CTGGGCTCCTGGTCTTTTGCGGATGTGCCGCAGCGTGTCGGCCCCACTCCGGTGCTTCAGGTTTTCGCCGTTCACGAAGA GCTGGAGCACATCCGTAAAACGCAGGAAGCCATCTGGGCCGGGCTGACCGGGCCGAAAGAGAGACACACTGAGGATCGC GGGCACATGGACGTCTTGACCCCTGATGGACACCGCTTCGCGCACCTTGTAAAAGTCCAGGTGGACTTTGTGCTGAAAAA CTTTGCGCAGAGAATGCGTTGA

\section{Amino acid}

MGLSEKVEFKTLDGLVLRGFLYSARAKGPAIVMTPGFNFPVSLLYHEVALGFQAAGITALVYDPRSVGRSDGLPRSDINPAKQSE DFSDAITFLKTKPVVDPKRIALWGYSLSAAAALMAAGLDPRVKLVVAVCPAPVPYNFEAPGKRRKYLDLAIRDRESQARGKEPFY VQYIGDSEETALFDYRKQRGMEELEYDEVVENLTKIAPGFRNEVTIQTLRRLGSWSFADVPQRVGPTPVLQVFAVHEELEHIRKT QEAIWAGLTGPKERHTEDRGHMDVLTPDGHRFAHLVKVQVDFVLKNFAQRMR

Table S5. List of primers used for cloning of apmlA and $a p m l B$

\begin{tabular}{c|c}
\hline Primer name & DNA sequence 5, to 3, \\
\hline apmlA_IFpUKpnI-FW & CCGGAATTCGAGCTCGGCAGACATGTCGGACCATAACC \\
apmlA_IFpUKpnI-RV & ACTACAGATCCCCGGGATTCAGCCGTACAGTGTAGG \\
apmlA_F1 & CGAGTACTTCGACTGGATCTG \\
apmlA_R1 & CAGATCCAGTCGAAGTACTCG \\
apmlB_IFpUNotI-FW & TTTGAGCTAGCGGCCATGATGGGTTTGAGTGAGAAGG \\
apmlB_IFpUNotI-RV & GTCACTAGTGCGGCCGACTACATACCGACTCAACG \\
\hline
\end{tabular}

Table S6. Summary of construction of expression plasmids for A. oryzae transformation.

\begin{tabular}{c|c|c|c}
\hline Plasmid name & Original vector & Gene 1 (KpnI site) & Gene 1 (NotI site) \\
\hline pUARA2- $a p m l A B$ & pUARA2 & apmlA & apmlB
\end{tabular}




\begin{tabular}{c|c|c|c} 
pUARA2-apmlA & pUARA2 & apmlA & \\
pUAdeA2-apmlB & pUAdeA2 & & apmlB \\
\hline
\end{tabular}

Table S7. Summary of A. oryzae transformant in this study.

\begin{tabular}{c|c|c}
\hline Transformant name & Plasmid 1 & Plasmid 2 \\
\hline AO- $a p m l A B$ & pUARA2-apmlAB & \\
AO-apmlA + apmlB & pUARA2-apmlA & pUAdeA2-apmlB \\
AO-apmlA & pUARA2-apmlA & \\
\hline
\end{tabular}



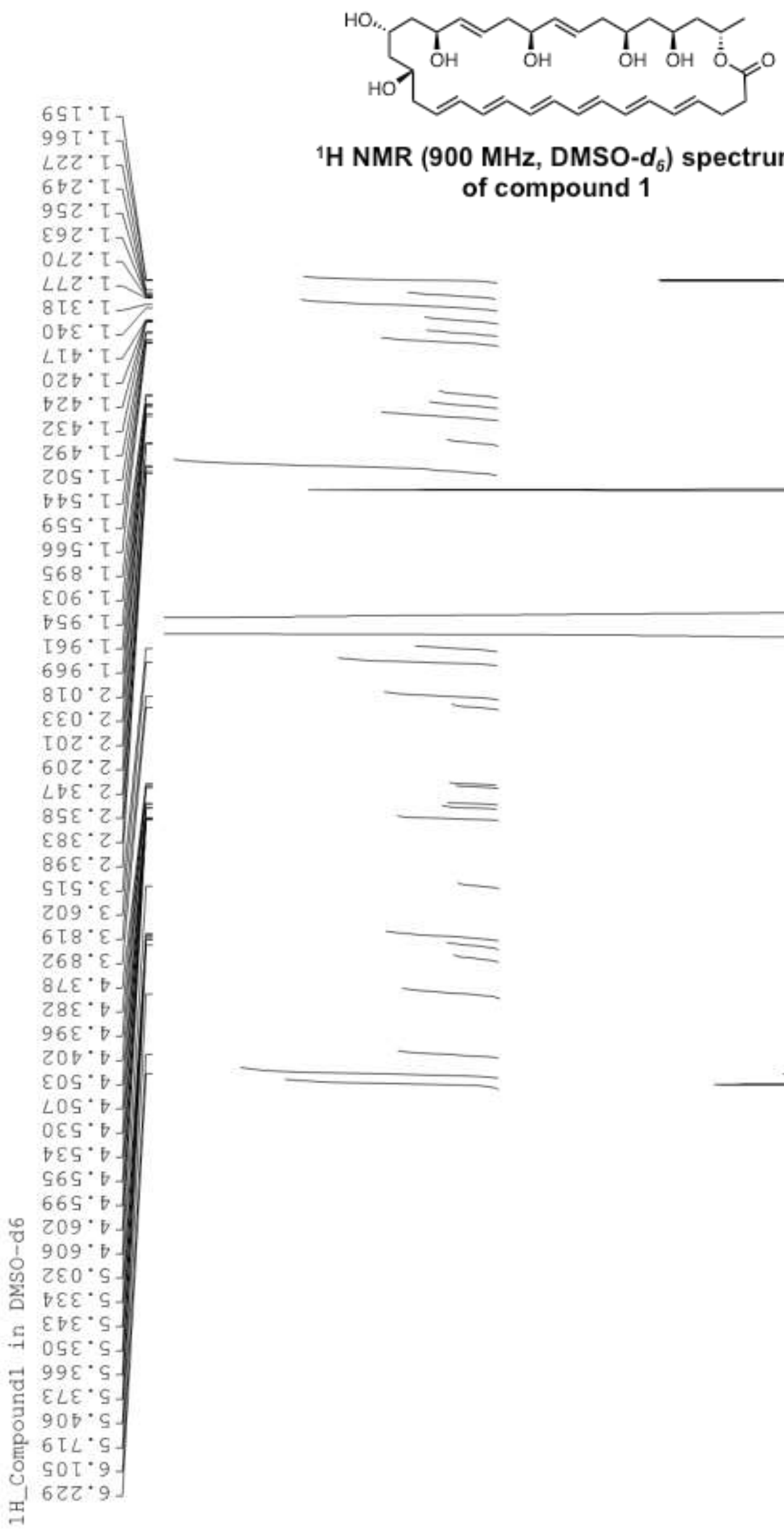

${ }^{1} \mathrm{H}$ NMR $\left(900 \mathrm{MHz}\right.$, DMSO- $\left.d_{6}\right)$ spectrum of compound 1
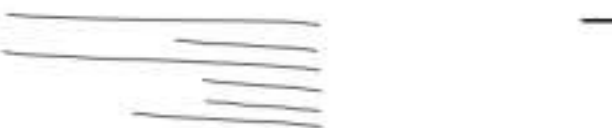

ก?
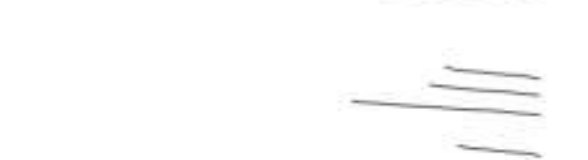

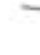
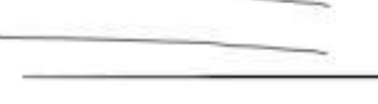


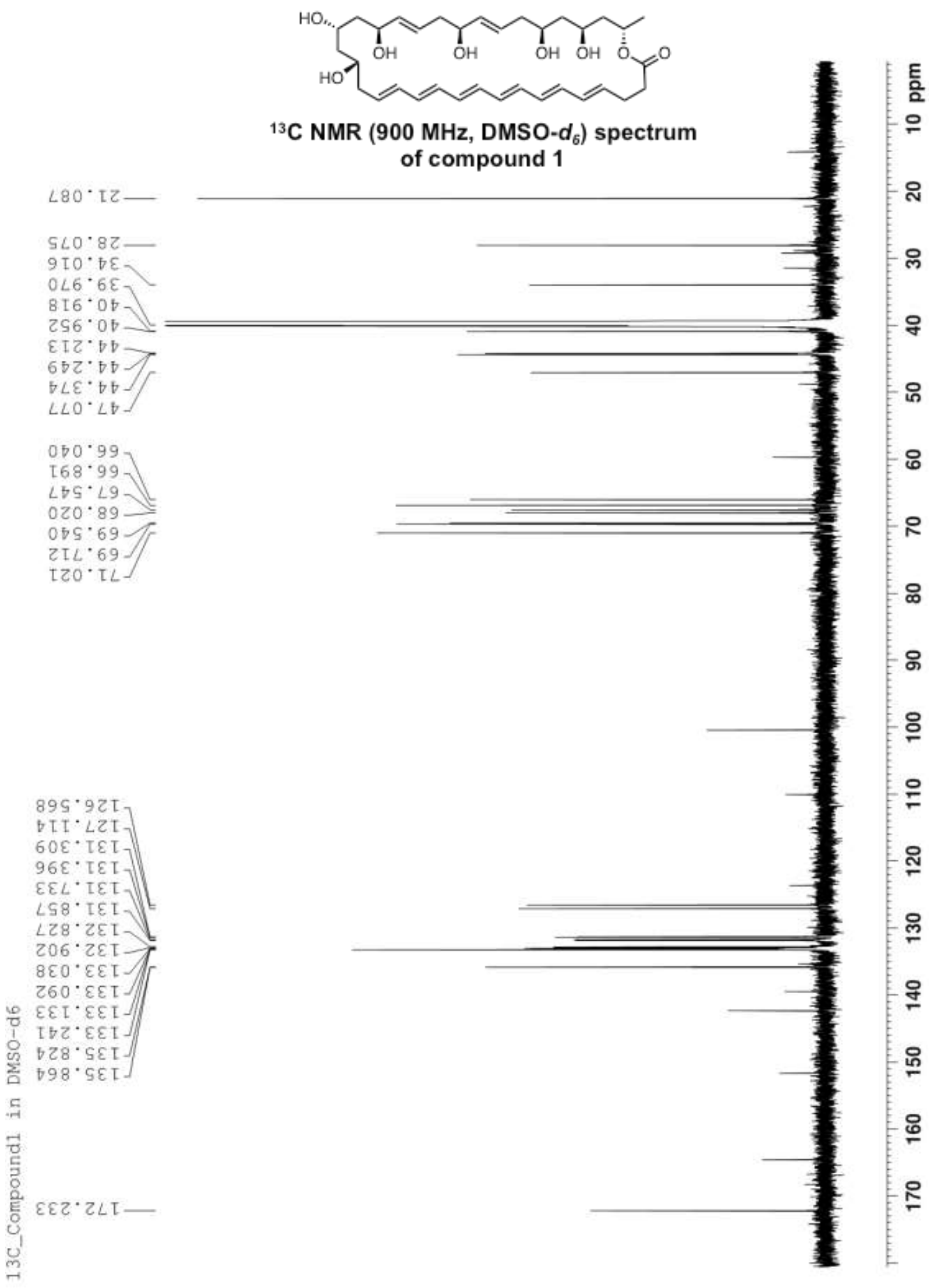




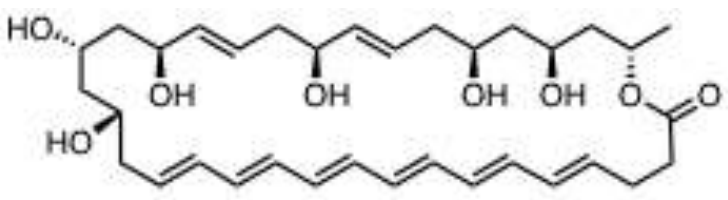

${ }^{1} \mathrm{H}-{ }^{1} \mathrm{H} \operatorname{COSY}$ (DMSO- $d_{6}$ ) spectrum of compound 1

틈 이 울 우

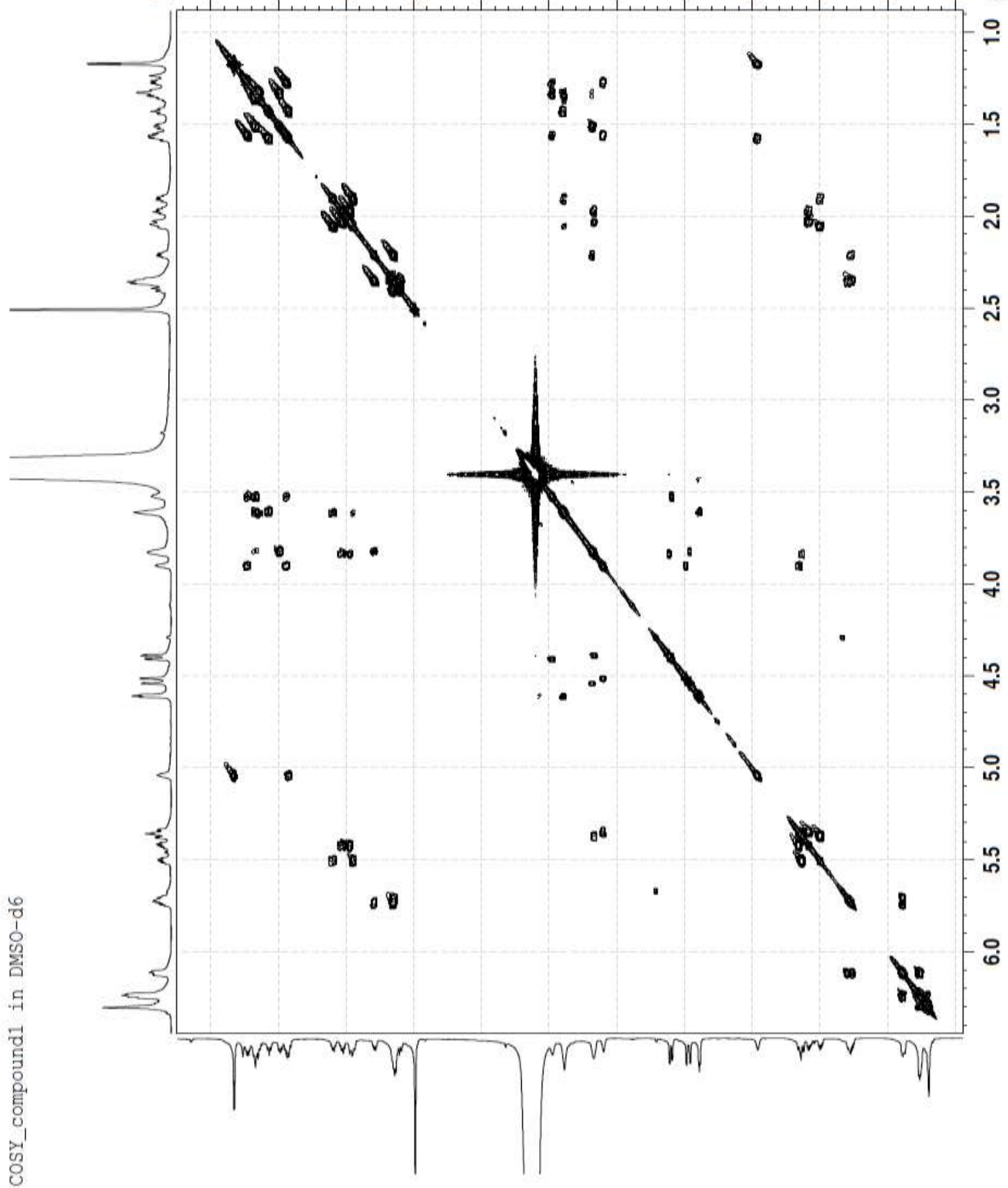



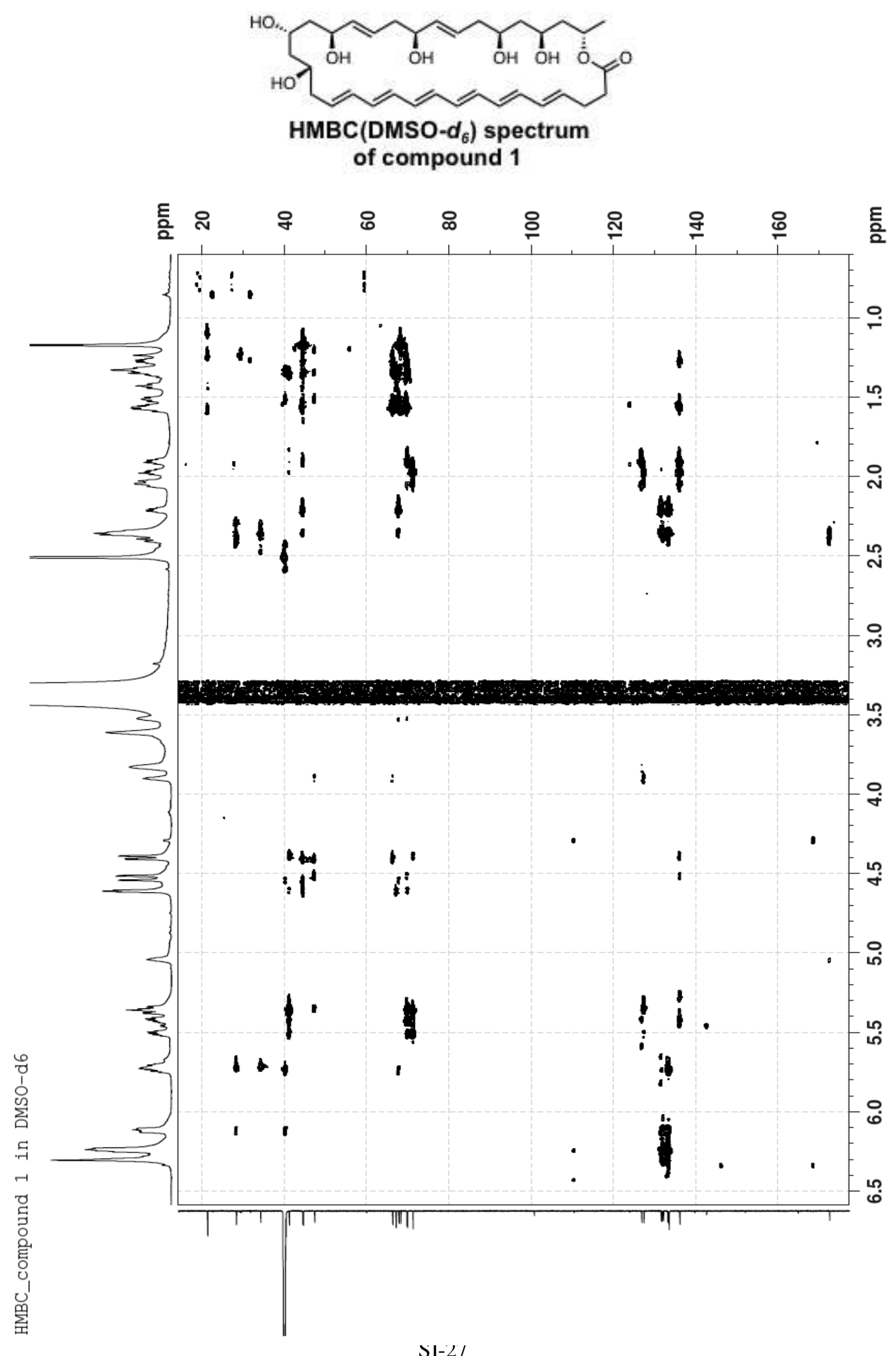


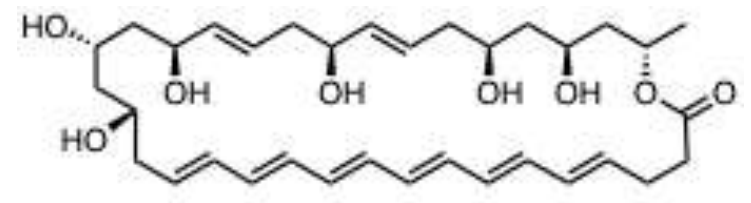

HSQC (DMSO- $d_{6}$ ) spectrum of compound 1

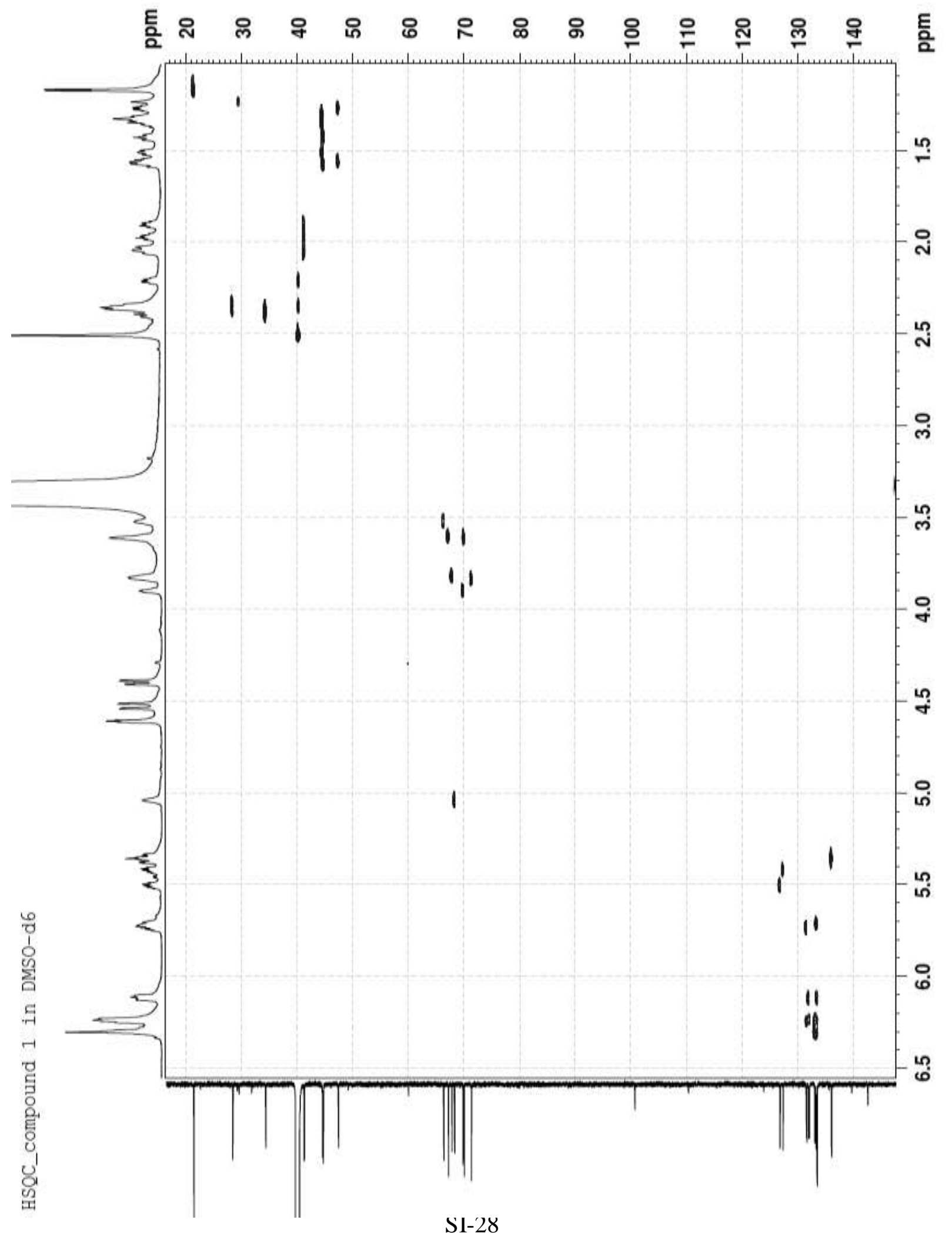




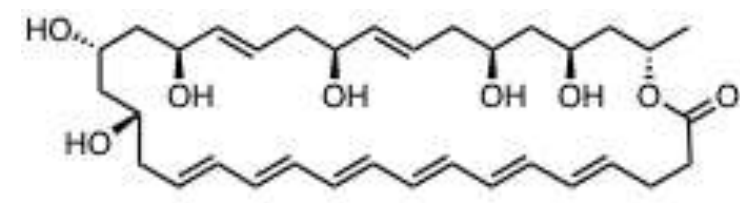

\section{NOESY(DMSO- $d_{6}$ ) spectrum} of compound 1

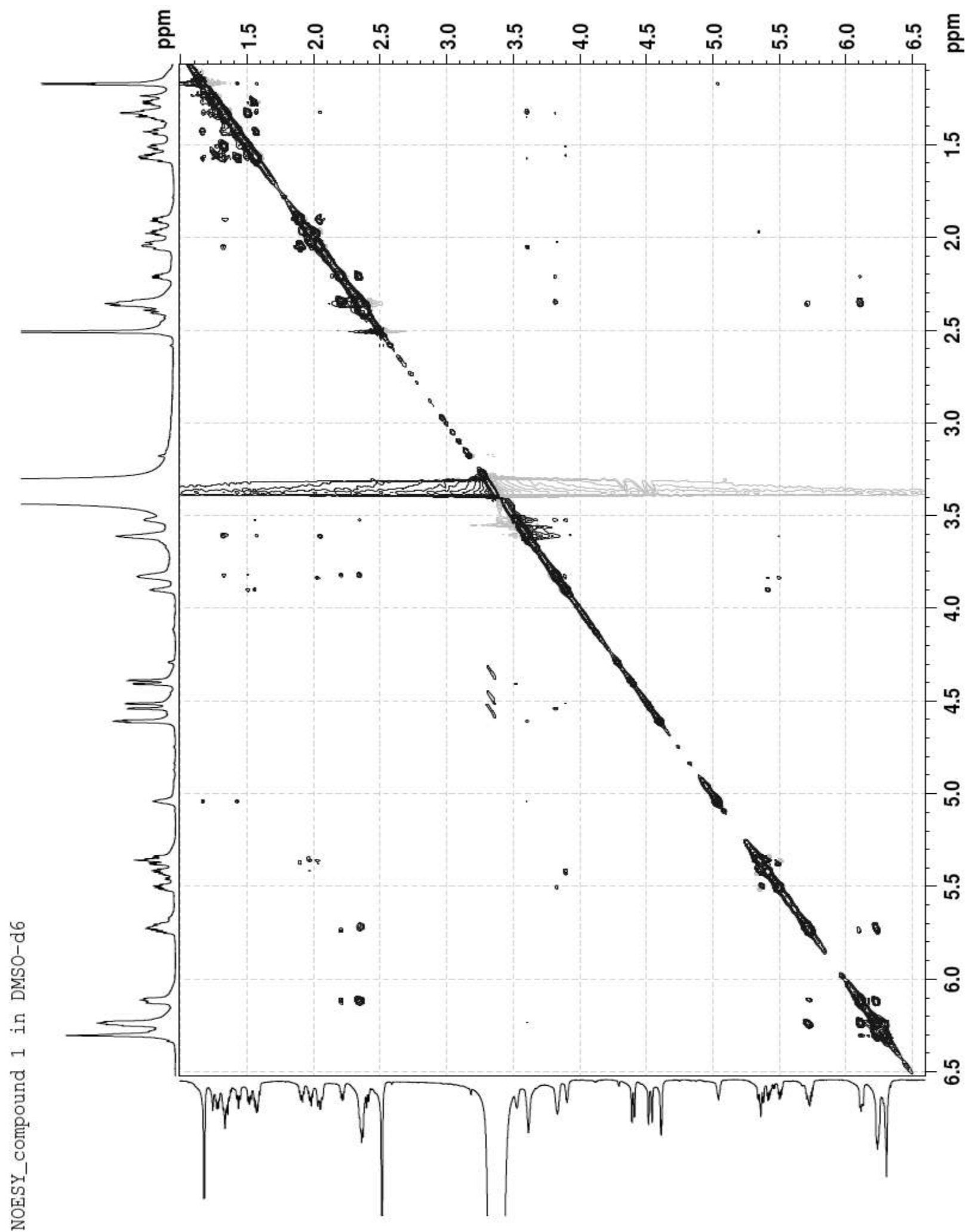




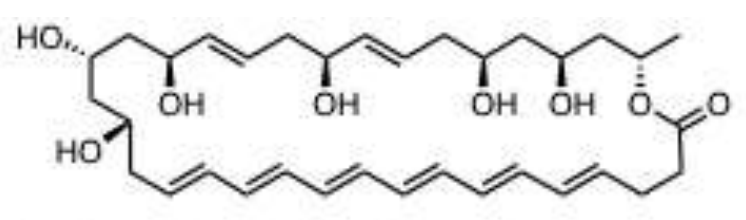

${ }^{1} \mathrm{H}-{ }^{-1} \mathrm{H}$ TOCSY(DMSO- $d_{6}$ ) spectrum
of compound 1

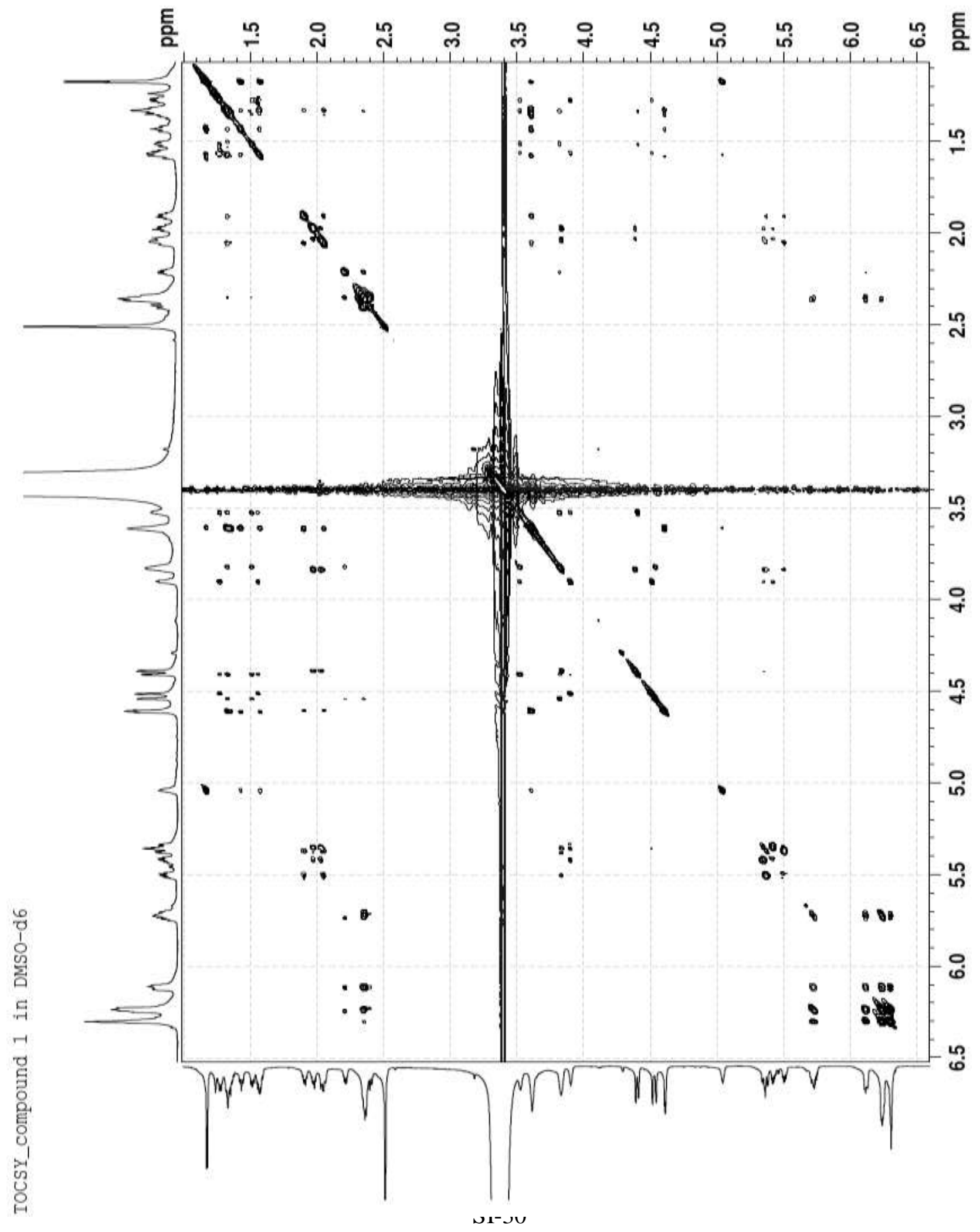




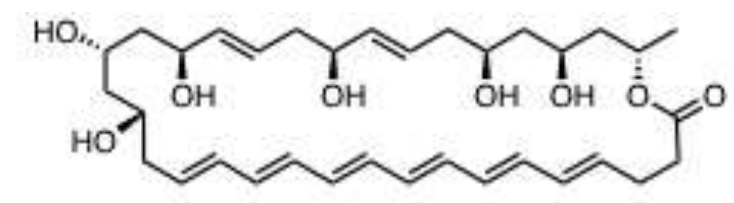

HSQC-TOCSY (DMSO- $d_{6}$ ) spectrum of compound 1

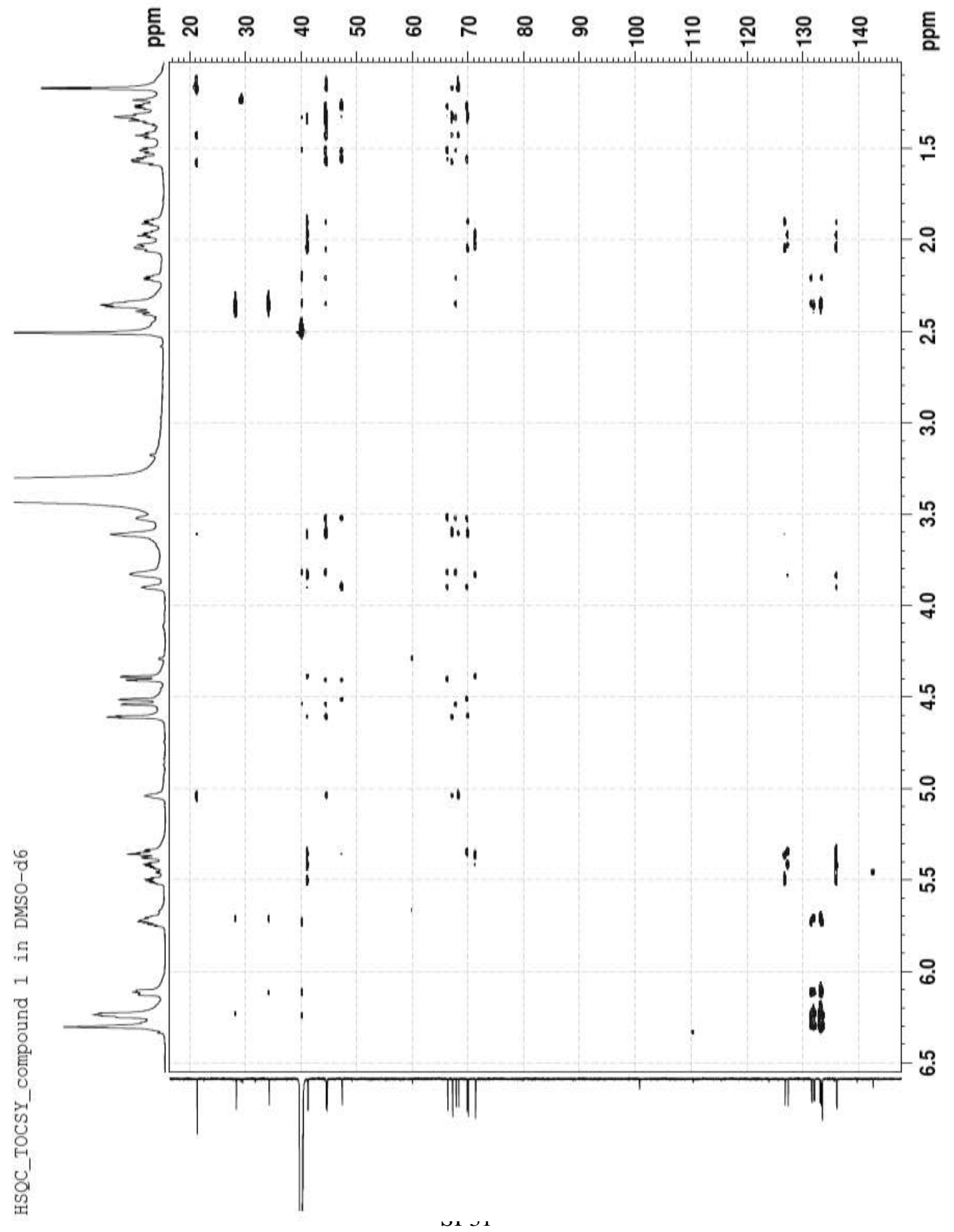



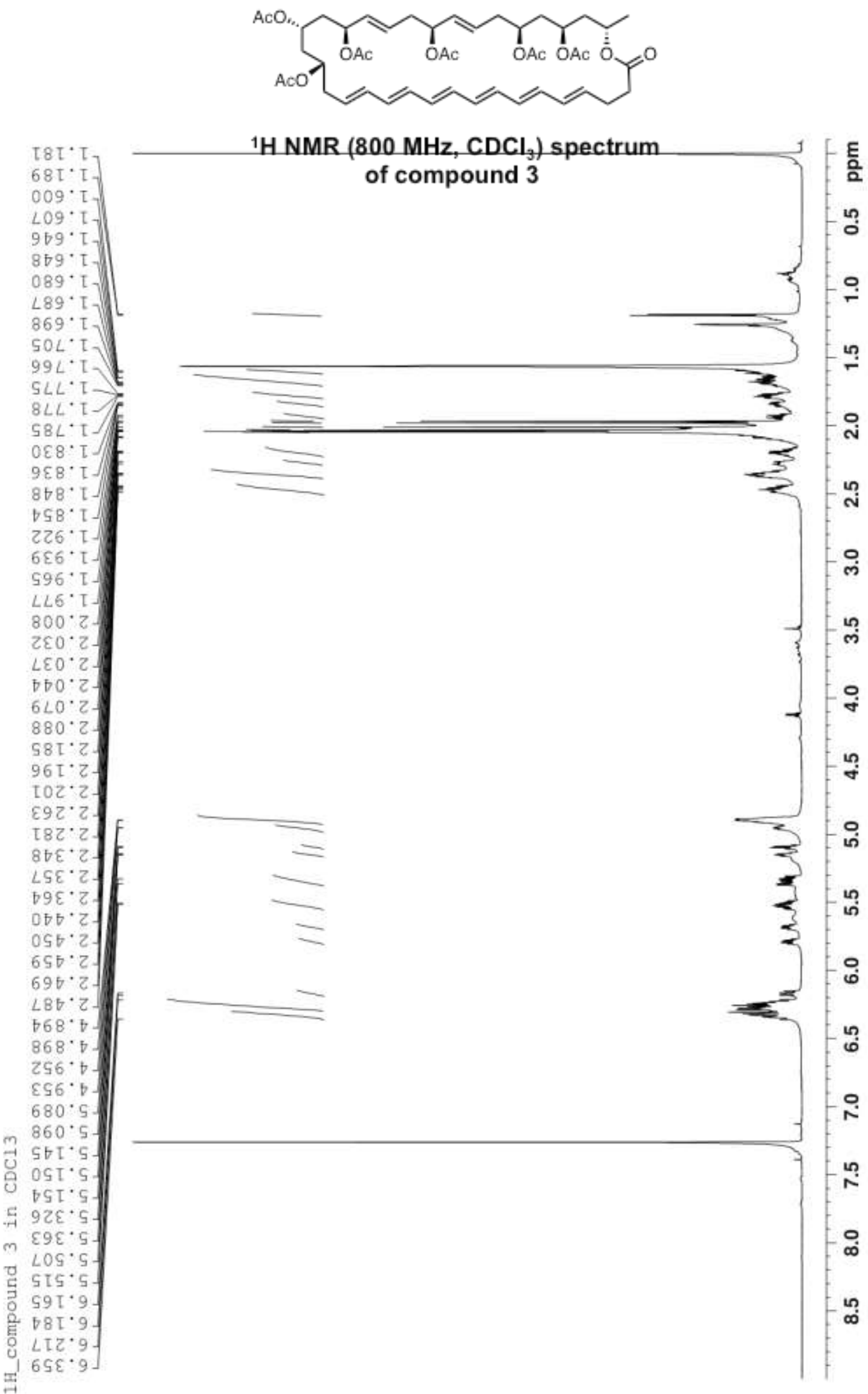
$\left.\begin{array}{l}085^{\circ} 0 z \\ 2 \tau 0^{\circ} \tau z \\ b \forall 0^{\circ} \tau z \\ \varepsilon \forall[\cdot \tau z \\ \tau \forall Z^{\circ} \tau z \\ 69 Z^{\circ}[z\end{array}\right]$

$66 \tau \cdot 8 Z$

$969^{\circ} 62$

$\forall 8 \forall^{\circ} \forall \varepsilon$

$68 L \cdot 9 \varepsilon$

228.

$956^{\circ} \mathrm{LE} / \mathrm{F}$

$\varepsilon \tau^{\circ} 8 \varepsilon$

$789^{\circ} 8 \varepsilon$

LEE $O E^{\circ} \mathrm{D}$

TEL. Ob]

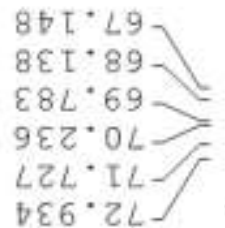

${ }^{13} \mathrm{C} \mathrm{NMR}\left(800 \mathrm{MHz}, \mathrm{CDCl}_{3}\right)$ spectrum

of compound 3

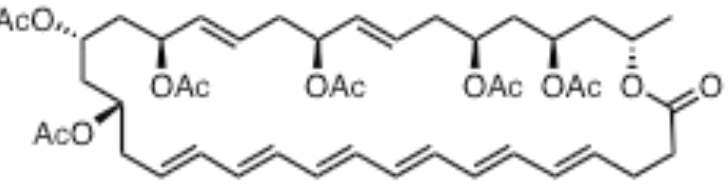

틈
우
잉

웅

ㅇํ

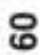

온

๕ి

8

웅

$990^{\circ} 8 Z \mathrm{I}$

I $\angle 9^{\circ} 82 \mathrm{I}$

$6 \varepsilon \mathrm{T} \cdot 0 \varepsilon \mathrm{I}$

$280^{\circ} 0 \varepsilon \mathrm{I}$.

бह७ $\nabla^{\circ}[\varepsilon[]$

$\forall 90^{\circ} \tau \varepsilon \tau_{7}$

I $\forall 0^{\circ} z \varepsilon \tau_{-}$

$88 \mathrm{I} \cdot z \varepsilon$

ZZ०० ZEI

$\angle 6 \theta^{\circ} 2 \varepsilon T$

$8\left[9^{\circ} Z \varepsilon[J\right.$

$m$ Z

$\rightarrow 0 \rightarrow 9^{\circ} \varepsilon \varepsilon[]$

Oि $099^{\circ} \varepsilon \varepsilon[$.

$8 \mathrm{SL}^{\circ} \varepsilon \varepsilon I$

ㄷ $\varepsilon\left[L^{\circ} \rightarrow \varepsilon \tau\right]$

m

T89.69T

Oह8.69 I

$9 Z I^{\circ} 0 \mathrm{LI}$

$6 \forall I^{\circ} 0 L I$

$882^{\circ} 0$ LI

SIS. $0 L I J$

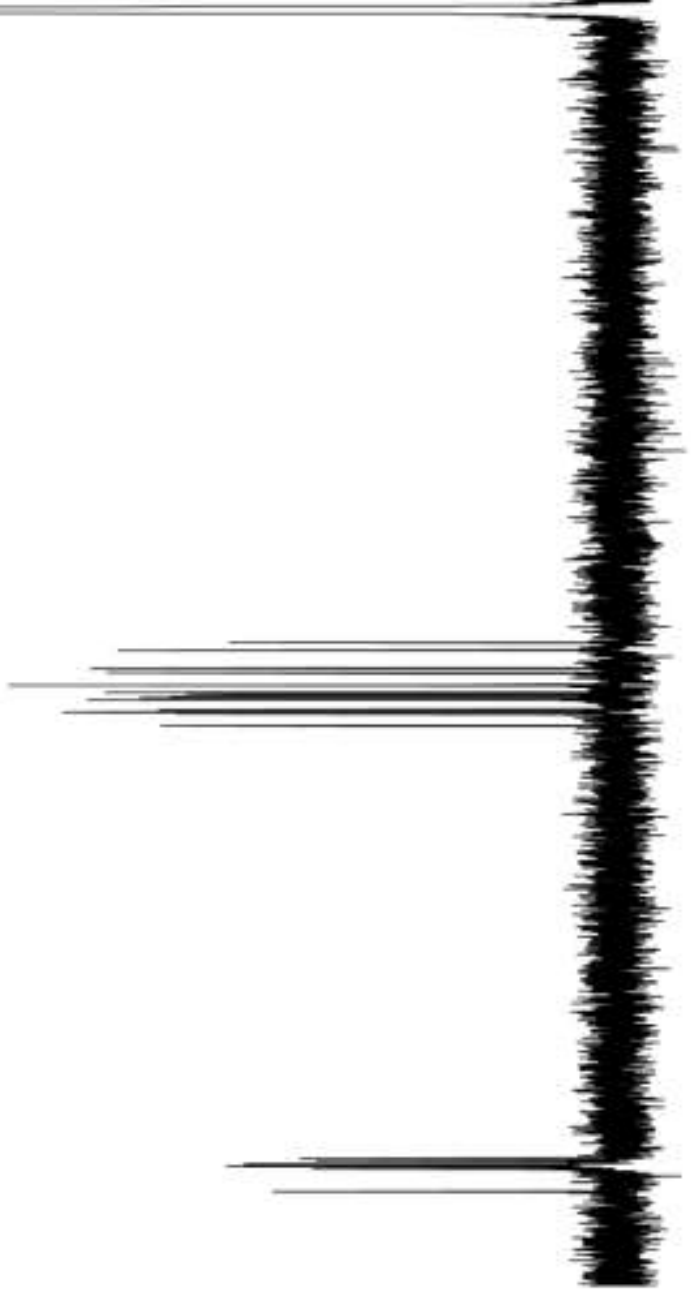

으

กิ

요

운

옹

웅

$\stackrel{ }{ }$ 


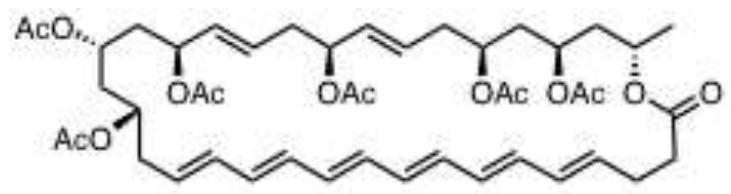

${ }^{1} \mathrm{H}-{ }^{-1} \mathrm{H} \cos Y\left(\mathrm{CDCl}_{3}\right)$ spectrum

of compound 3

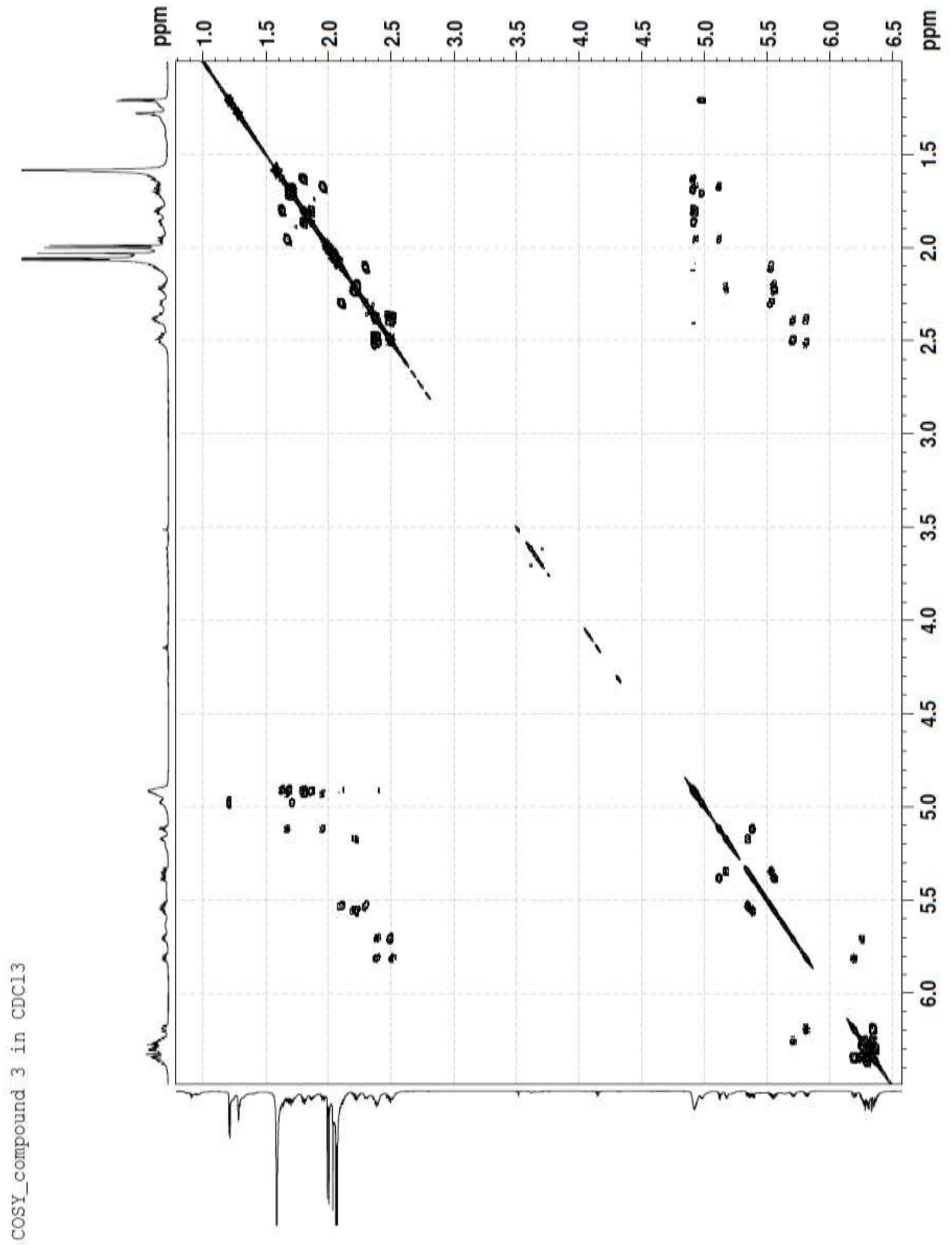




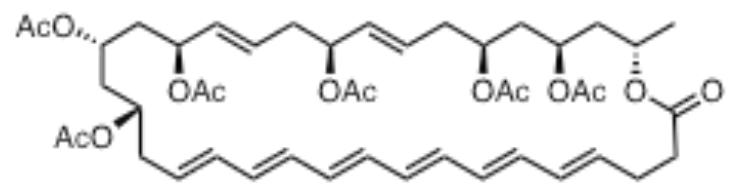

HMBC $\left(\mathrm{CDCl}_{3}\right)$ spectrum

of compound 3

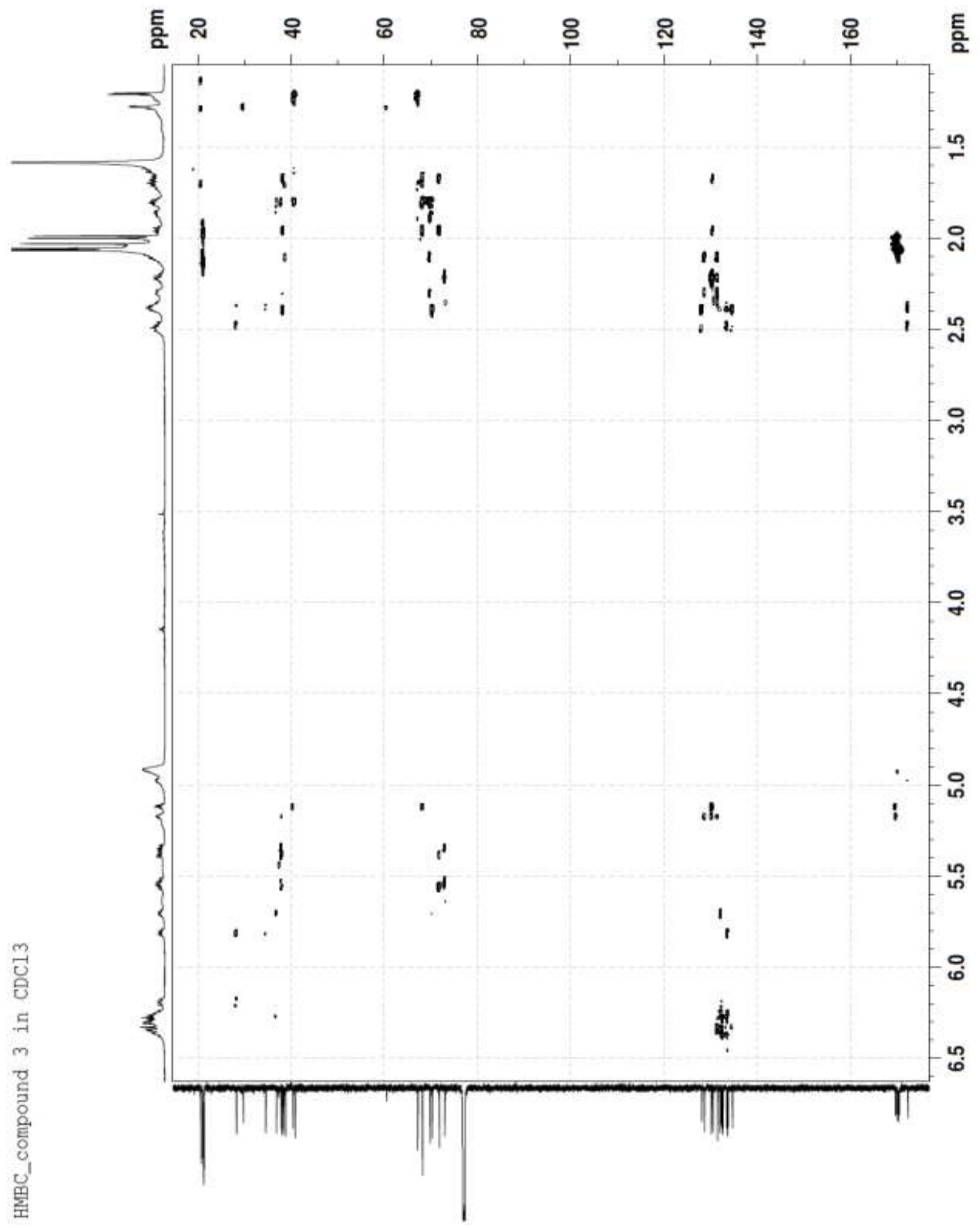



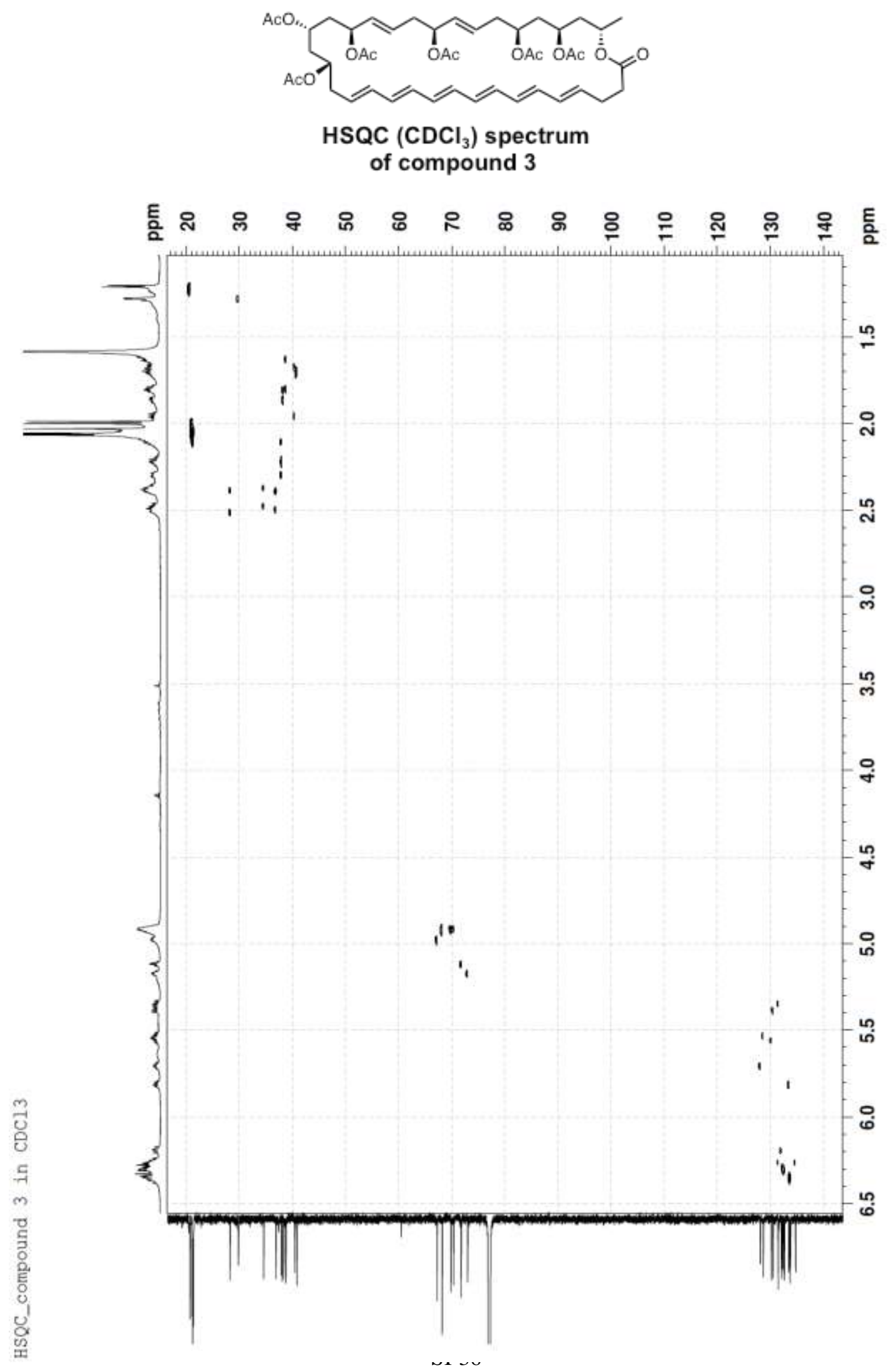

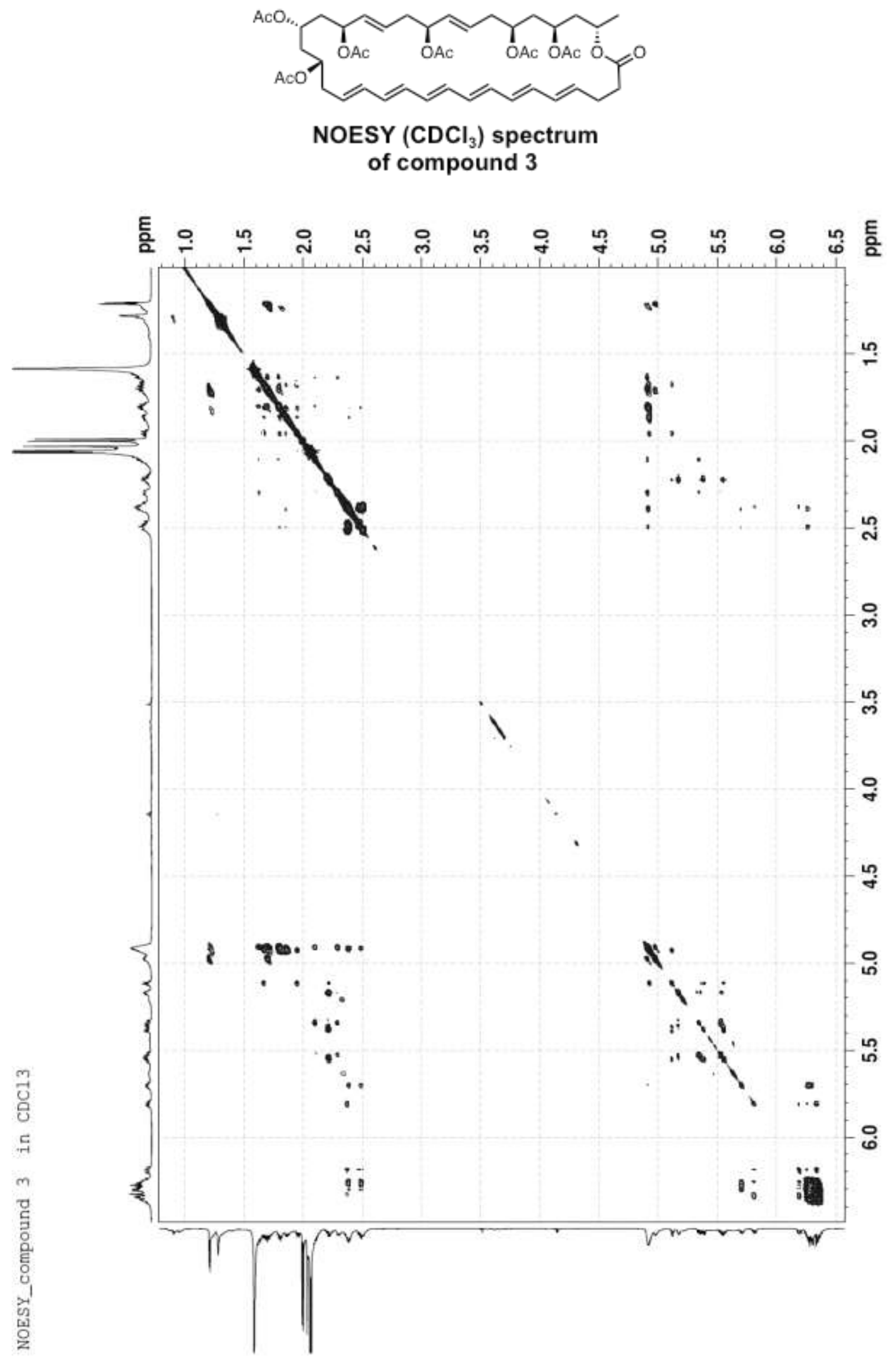


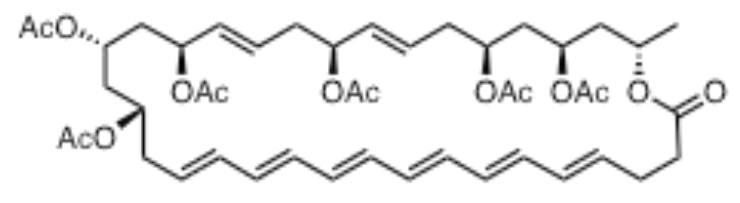

HSQC-TOCSY $\left(\mathrm{CDCl}_{3}\right)$ spectrum of compound 3

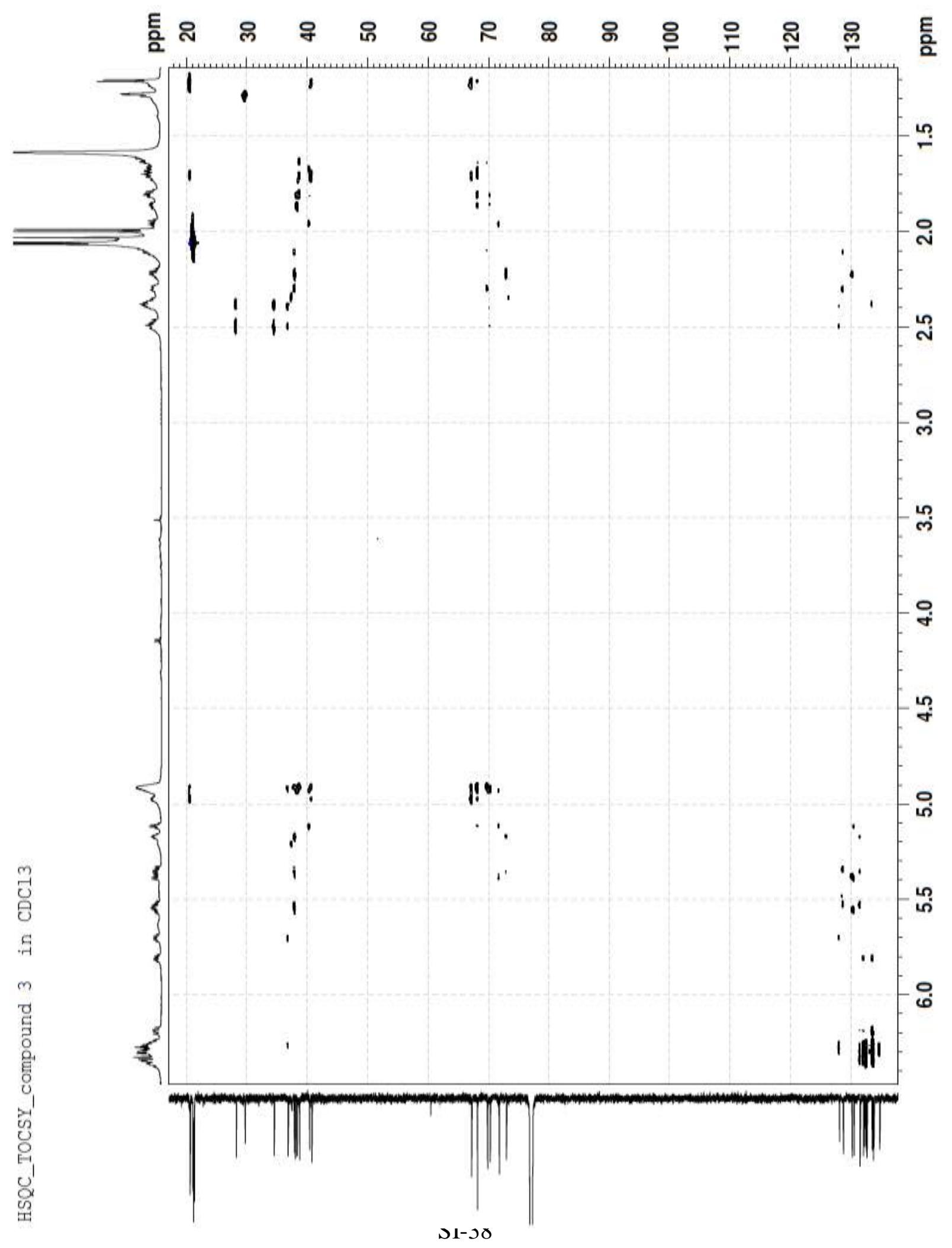




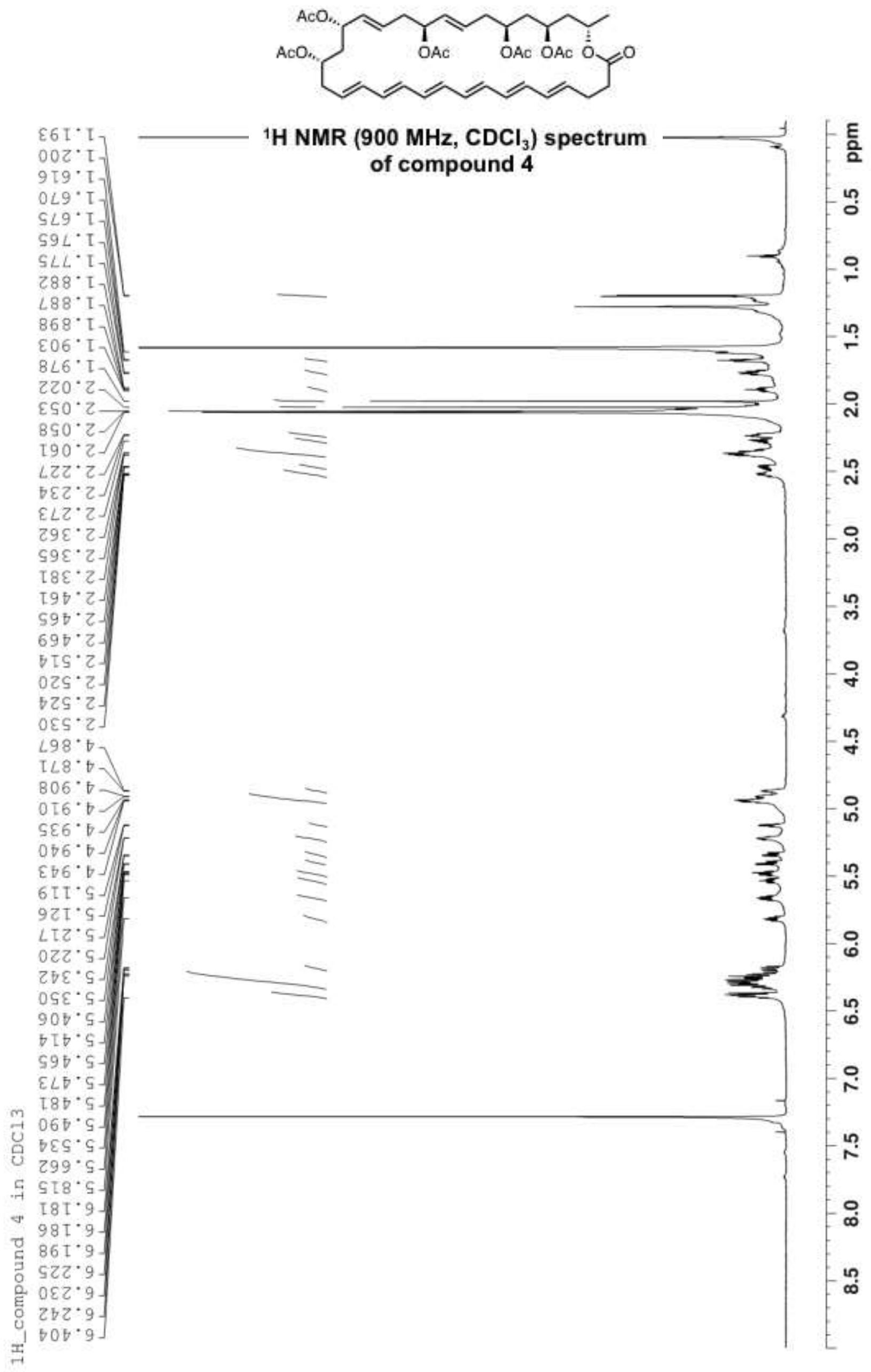




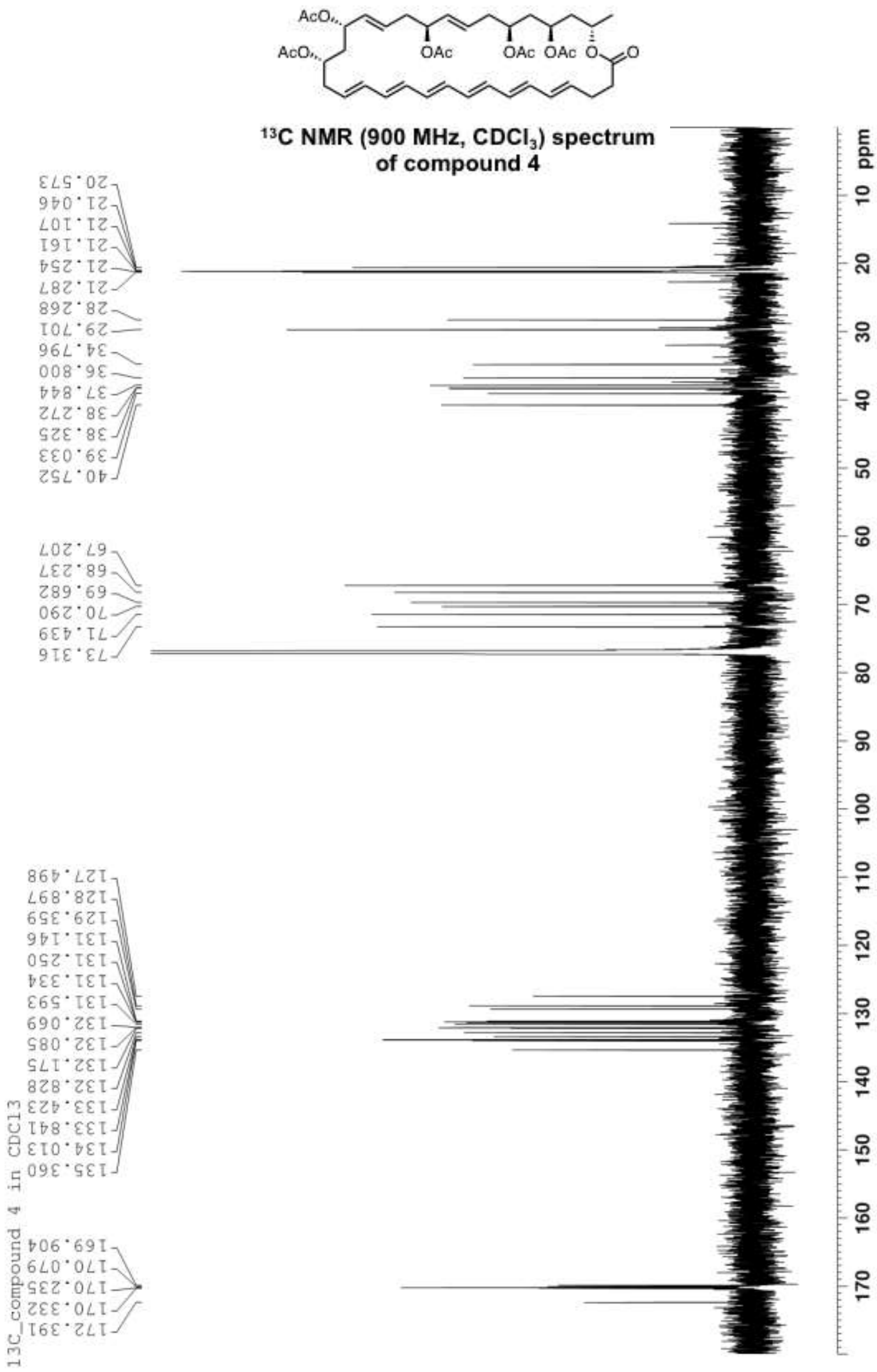




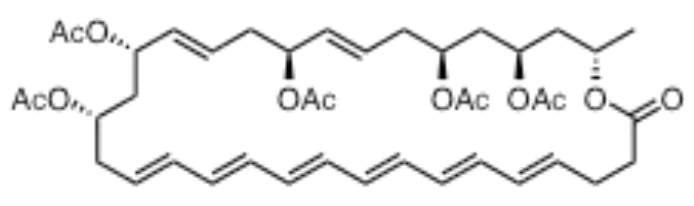

${ }^{1} \mathrm{H}-{ }^{-1} \mathrm{H} \operatorname{COSY}\left(\mathrm{CDCl}_{3}\right)$ spectrum of compound 4

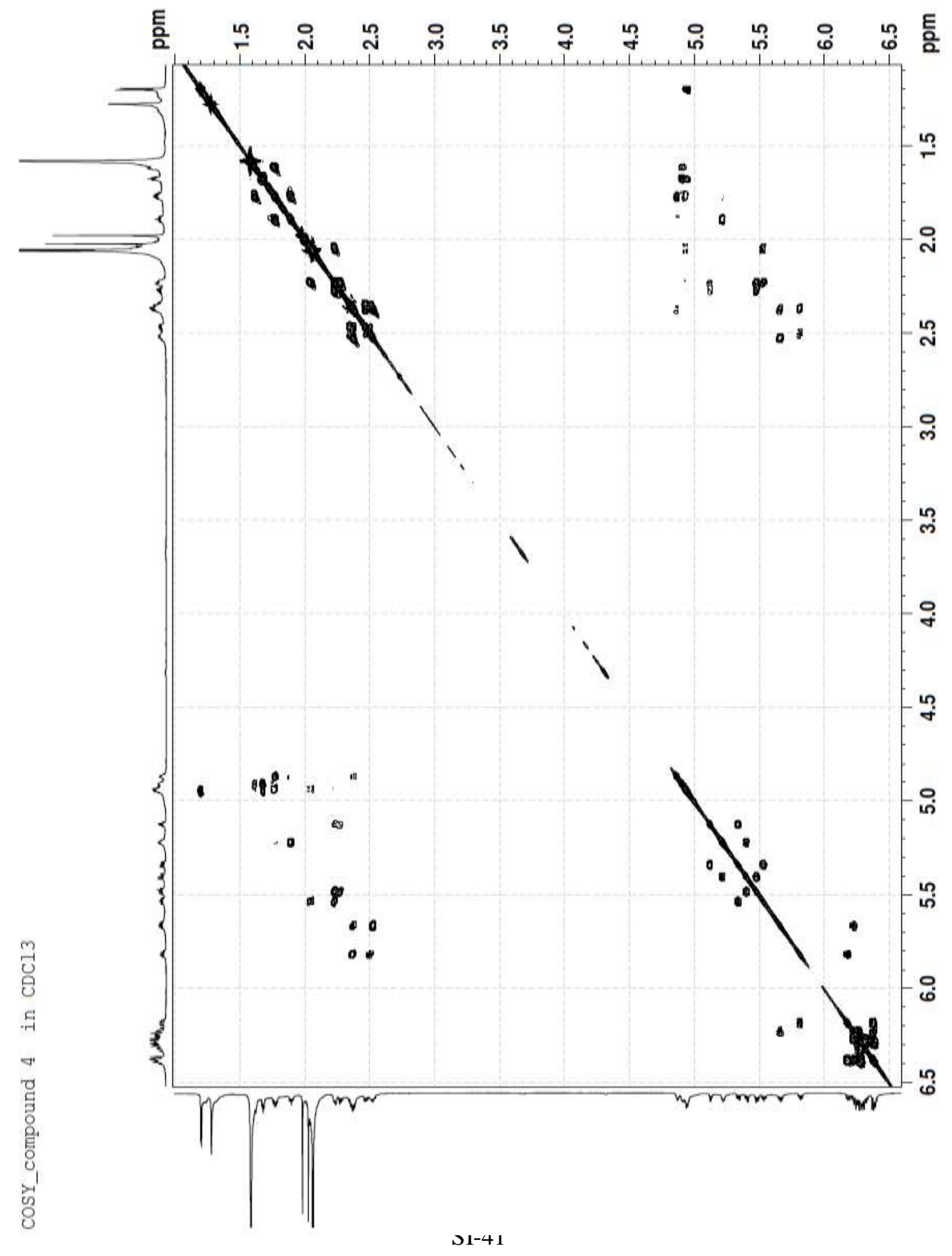




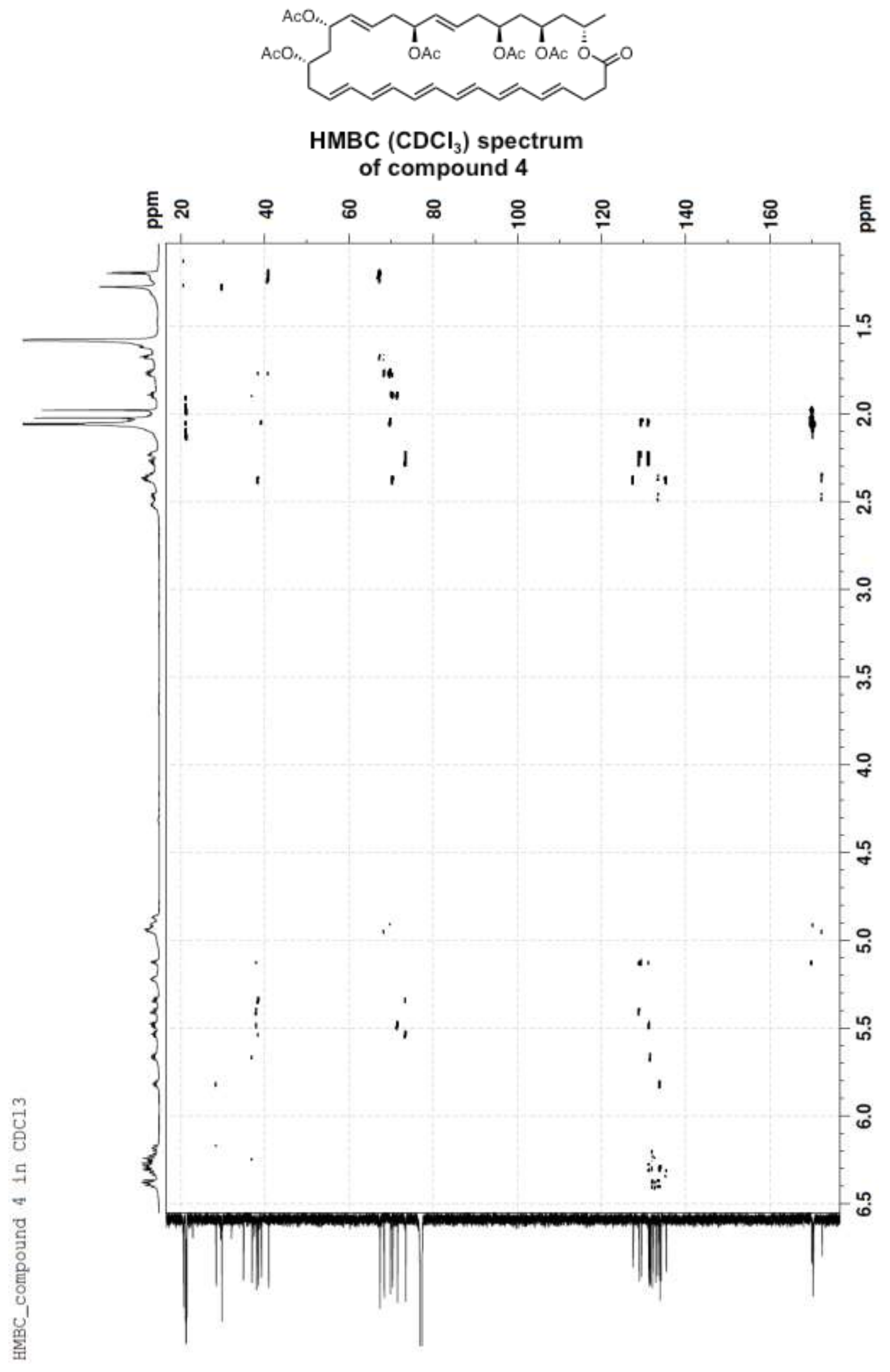




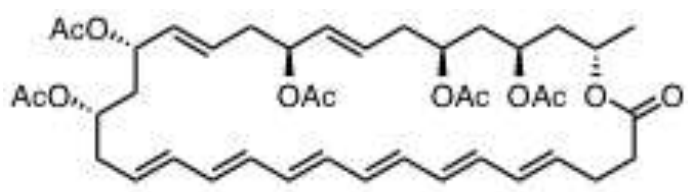

HSQC $\left(\mathrm{CDCl}_{3}\right)$ spectrum

of compound 4

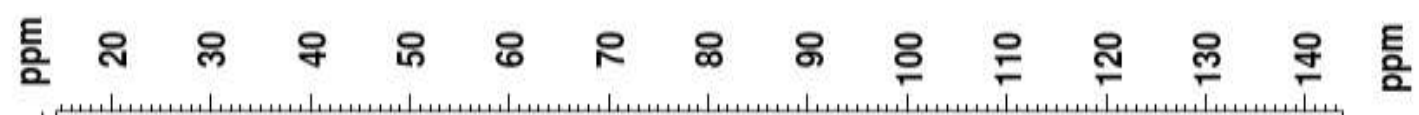

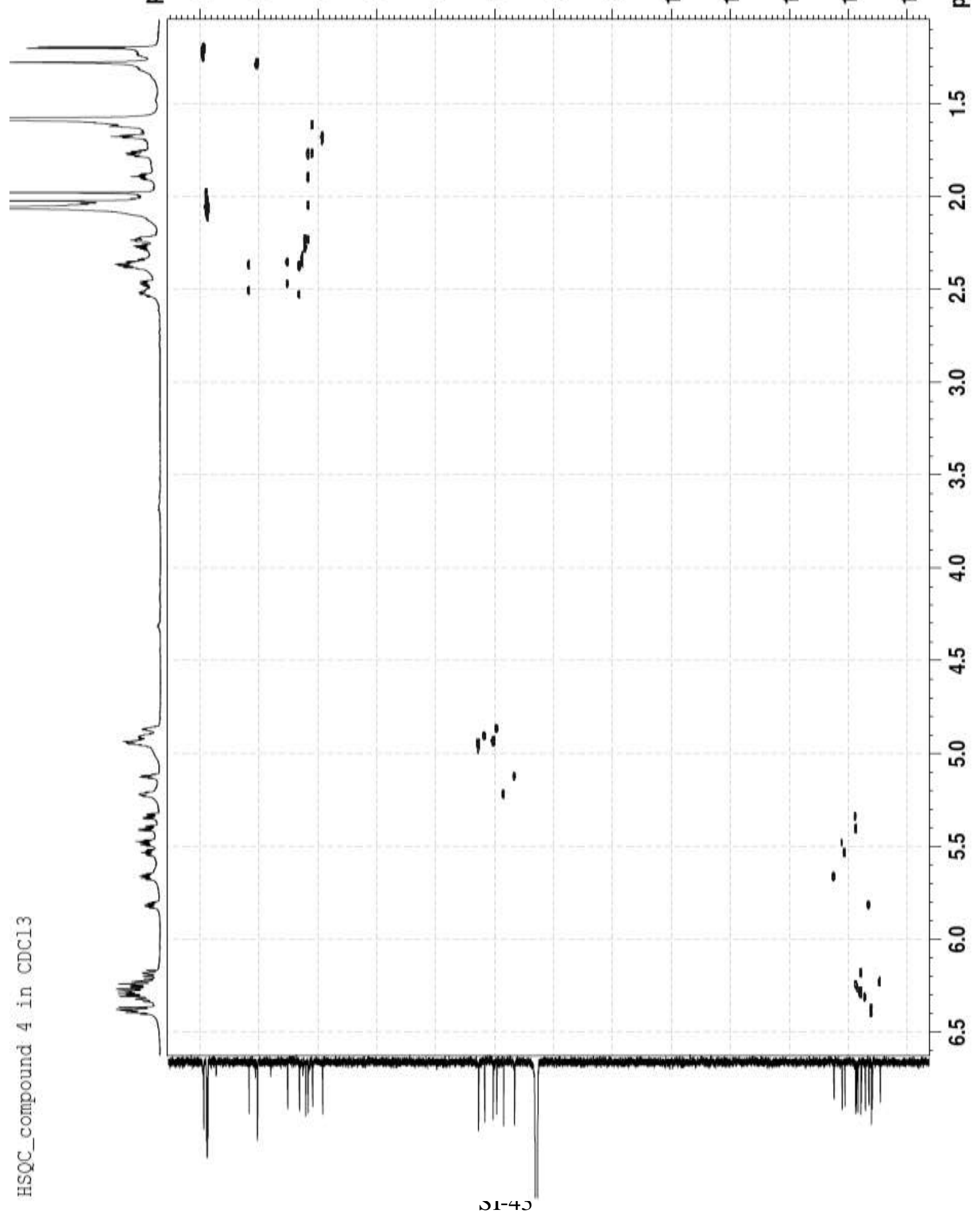




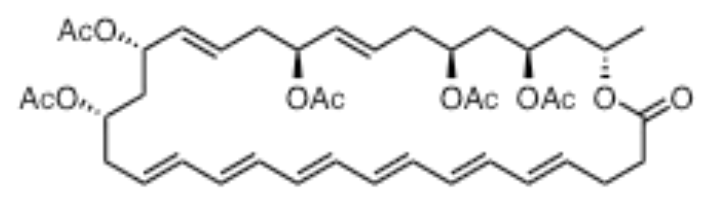

${ }^{1} \mathrm{H}-{ }^{1} \mathrm{H}$ TOCSY $\left(\mathrm{CDCl}_{3}\right)$ spectrum of compound 4

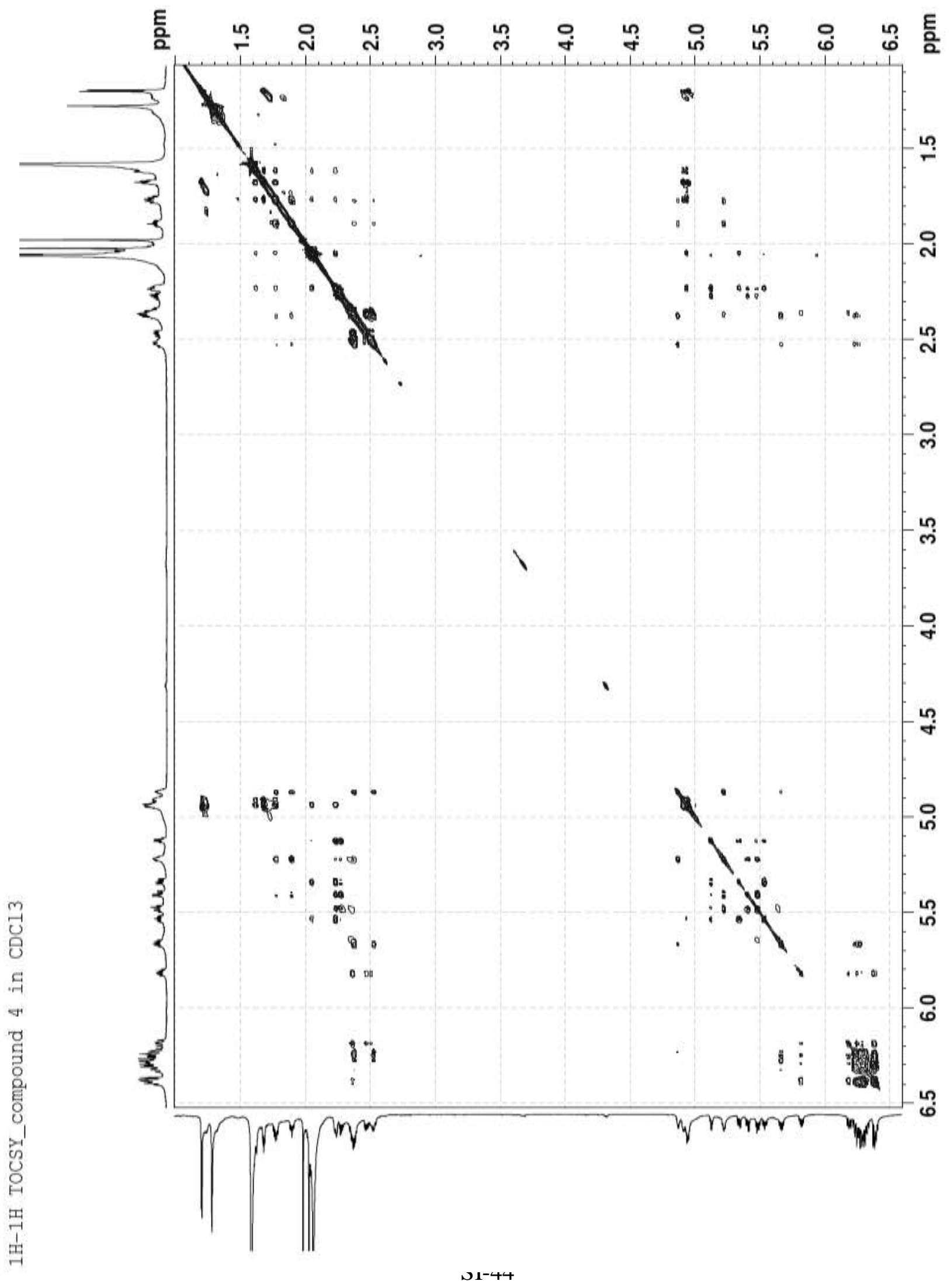




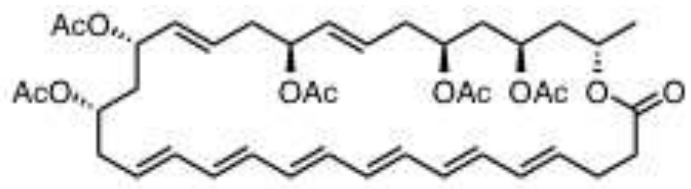

HSQC-TOCSY $\left(\mathrm{CDCl}_{3}\right)$ spectrum of compound 4

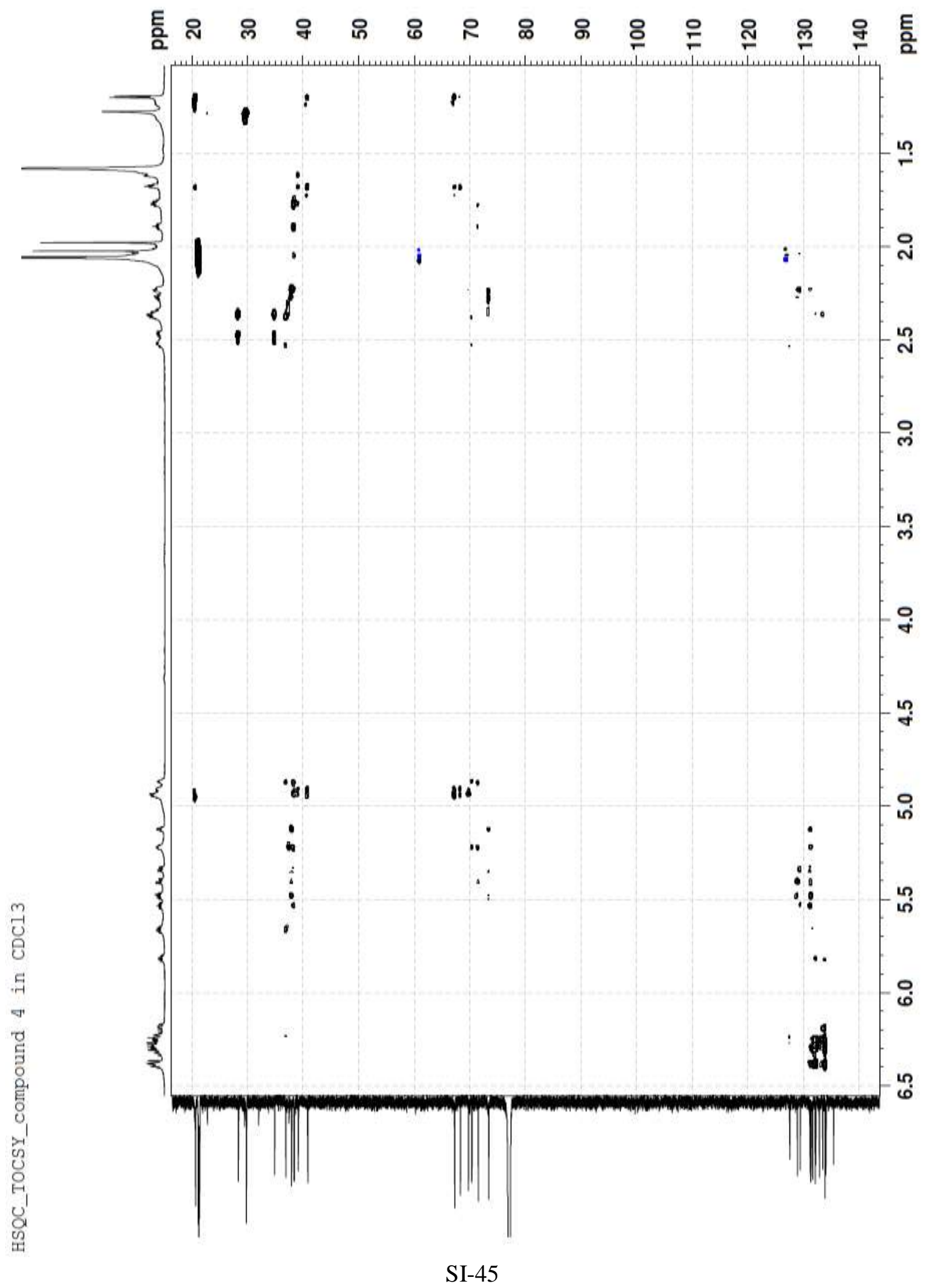

